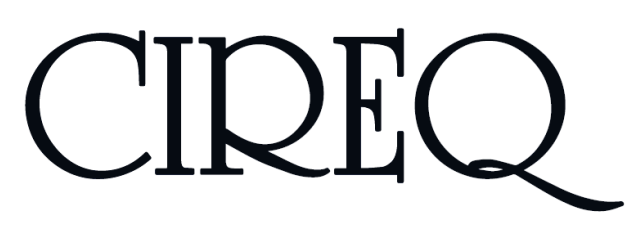

Centre interuniversitaire de recherche en économie quantitative

\title{
Cahier 13-2019
}

Inputs, Incentives, and Self-selection at the Workplace

Francesco Amodio and Miguel A. Martinez-Carrasco

www.cireqmontreal.com

y@CIREQMTL

If facebook.com/CIREQ 


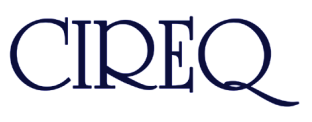

Le Centre interuniversitaire de recherche en économie quantitative (CIREQ) regroupe des chercheurs dans les domaines de l'économétrie, la théorie de la décision, la macroéconomie et les marchés financiers, la microéconomie appliquée ainsi que l'économie de l'environnement et des ressources naturelles. Ils proviennent principalement des universités de Montréal, McGill et Concordia. Le CIREQ offre un milieu dynamique de recherche en économie quantitative grâce au grand nombre d'activités qu'il organise (séminaires, ateliers, colloques) et de collaborateurs qu'il reçoit chaque année.

The Center for Interuniversity Research in Quantitative Economics (CIREQ) regroups researchers in the fields of econometrics, decision theory, macroeconomics and financial markets, applied microeconomics as well as environmental and natural resources economics. They come mainly from the Université de Montréal, McGill University and Concordia University. CIREQ offers a dynamic environment of research in quantitative economics thanks to the large number of activities that it organizes (seminars, workshops, conferences) and to the visitors it receives every year.

\title{
Cahier 13-2019
}

\section{Inputs, Incentives, and Self-selection at the Workplace}

\author{
Francesco Amodio and Miguel A. Martinez-Carrasco
}


Dépôt légal - Bibliothèque nationale du Canada, 2019, ISSN 0821-4441

Dépôt légal - Bibliothèque et Archives nationales du Québec, 2019

ISBN-13 : 978-2-89382-753-7 


\title{
Inputs, Incentives, and Self-selection At the Workplace
}

\author{
Francesco Amodio* Miguel A. Martinez-Carrasco ${ }^{\dagger}$
}

December 11, 2019

\begin{abstract}
This paper studies how asymmetric information over inputs affects workers' response to incentives and self-selection at the workplace. Using daily records from a Peruvian egg production plant, we exploit a sudden change in the worker salary structure and find that workers' effort, firm profits, and worker participation change differentially along the two margins of input quality and worker type. Firm profits increase differentially from high productivity workers, but absenteeism and quits of these workers also differentially increase. Evidence shows that information asymmetries over inputs between workers and managers shape the response to incentives and self-selection at the workplace.
\end{abstract}

Keywords: asymmetric information, input heterogeneity, incentives, self-selection.

JEL Codes: D22, D24, J24, J33, M11, M52, M54, O12.

*francesco.amodio@mcgill.ca, Department of Economics and Institute for the Study of International Development, McGill University, Leacock Building 514, 855 Sherbrooke St. West, Montreal, QC H3A 2T7.

†ma.martinezc1@uniandes.edu.co, School of Management, Universidad de Los Andes, Calle 21 No. 1-20, Bogotá, Colombia. 


\section{Introduction}

In many workplaces, workers produce output combining their effort with some other production input. From garment factory workers to healthcare professionals, the quality of inputs matters for productivity. Workers themselves are also different from each other in their willingness to exert effort. The amount of information available to managers on both input and worker heterogeneity restricts the set of implementable contracts. How does asymmetric information between workers and managers over input quality and worker type affect the response to incentives and worker self-selection?

Providing an empirical answer to these questions is challenging for several reasons. First, individual production records are not always maintained by firms, and usually not made available to external researchers. Second, the same is true for information on inputs that are assigned to individual workers, as input quality may be unknown to managers. Third, in order to exploit meaningful variation in input quality and derive credible estimates of workers' permanent productivities, all this information needs to be available for a sufficiently long time period. Finally, and most importantly, studying both incentive and self-selection effects requires variation in the pay scheme.

We overcome all these limitations using data from an egg producing plant in rural Peru (Amodio and Martinez-Carrasco 2018). Workers are assigned batches of hens of heterogeneous quality, exert effort to feed them, and collect eggs as output. In the first interval of the sampling period, workers are paid a piece rate that increases with both the amount of food they distribute and the amount of eggs they collect. At a given point in time, the firm decided to change to a bonus scheme that rewards workers based on output only. We exploit this change in incentives combined with information on inputs and output to identify the heterogeneous response to incentives along the two margins of input quality and worker type. We find that both margins of heterogeneity matter. In particular, firm profits increase differentially from high productivity workers. Yet, these same workers are differentially more likely to skip a day of work without consent and to quit altogether after the implementation of the new incentive scheme. Evidence shows that asymmetric information over inputs and workers affects the response to incentives 
and self-selection at the workplace.

First, to guide the empirical analysis, we develop a simple principal-agent model that describes the setting of our analysis and captures the mechanisms we are interested in. Heterogeneous workers use inputs of heterogeneous quality and exert effort to produce noisy output. Effort and output are observable to the management, but both input quality and worker type are not, as they are only known to the worker. The asymmetry of information over input quality prevents the management from writing a contract that specifies the level of effort that the worker should exert, as that changes with unobserved input quality. In addition, workers are risk-averse and cannot bear the full risk associated with the volatility of production. As a result, the management implements a linear contract that rewards workers for both output and effort. We take this wage structure as given, and characterize the optimal worker's effort choice and how it changes with the weight attached to both performance measures. The main model prediction is that, if input quality changes the sensitivity of output to effort, an increase in the weight attached to output will change worker's effort differentially according to the quality of inputs they handle. Workers of different type will also respond to the change to different extents, with implications for firm profits and worker self-selection as captured by absenteeism and retention.

Second, we take the model to the data. We exploit the change in the piece rate bonus formula implemented by the firm, and find evidence that is consistent with the model predictions. We measure input quality using information on the expected productivity of hens as provided by a third bird supplier company, and derive a measure of workers' permanent productivity or type using data from the period prior to the incentive change. We find that, when incentives on output increase and those on food distributed decrease, workers reduce their feeding effort. The fall is significantly larger for workers handling inputs of higher quality, and for those with higher permanent productivity. This is consistent with the model predictions and the evidence showing that output becomes less sensitive to feeding effort as input quality increases.

Third, we investigate the heterogeneous effects of changing incentives on output, firm profits, and worker self-selection. Output does not change differentially according to the quality of inputs or worker type. At the same time, wages decrease and output quality increases differ- 
entially for high productivity workers. These workers also distribute differentially less food, a costly input for the firm. It follows that firm profits increase differentially from workers with higher permanent productivity. Finally, we find that high productivity workers are differentially and significantly more likely to skip a day of work without consent and to quit the job after the change is implemented. These results altogether indicate that unobserved input and worker heterogeneity matters in shaping worker's effort response to incentives and their effectiveness in raising firm profits, and that incentive contracts have implications for worker absenteeism and retention (Lazear 2000). As time goes by, the most productive workers leave the firm following the change in incentives.

Our paper builds upon and contributes to several strands of the literature. A large theoretical literature exists on the trade-offs involved in performance pay, and the use of multiple performance measures (e.g., Hölmstrom 1979; Holmstrom and Milgrom 1987; Baker 1992). Starting with the seminal work of Lazear (2000), a number of empirical studies have provided convincing evidence that performance pay increases output (Prendergast 1999). Importantly, Black and Lynch (2001) use data from a nationally representative sample of US businesses and show that the relationship between workplace practices and productivity is shaped by how such practices are actually implemented.

The most recent empirical literature has devoted increasing attention to working arrangements in developing countries, partly because of the higher prevalence of piece rate pay. Using a two-stage field experiment in Malawi, Kim, Kim, and Kim (2019) provide evidence on how career and wage incentives affect labor productivity through self-selection and incentive effect channels. Guiteras and Jack (2018) also implement a field experiment in rural Malawi to separately identify the effects of worker selection and incentives on output. They find evidence that piece rate incentives increase output only through an incentive effect. Jayaraman, Ray, and de Véricourt (2016) study a contract change for tea pluckers on an Indian plantation and show evidence of short-term behavioral responses. Other studies show that the response to workplace incentives changes with the degree of social connectedness (Bandiera, Barankay, and Rasul 2010), ethnic diversity (Hjort 2014), and worker's self-control (Kaur, Kremer, and 
Mullainathan 2015).

Our study shows that the presence of asymmetric information within organizations along the specific margins of input quality and worker type shapes the response to monetary incentives and thus the effectiveness of performance pay in raising productivity and profits. We show that both channels of incentive and self-selection effects are affected. We thus enhance our understanding of the implications of input or task heterogeneity at the workplace, a common feature of many working environments (Adhvaryu, Kala, and Nyshadham 2019; Adhvaryu, Nyshadham, and Tamayo 2019; Menzel 2019; Amodio and Martinez-Carrasco 2018). Our findings also relate to those of Atkin, Chaudhry, Chaudry, Khandelwal, and Verhoogen (2017), who show how information asymmetries between workers and managers can slow down or prevent the adoption of productivity-enhancing technologies. More generally, we contribute to a growing literature that studies the role of human resource management in explaining productivity differences across firms and countries (Bloom and Van Reenen 2007; Bloom, Mahajan, McKenzie, and Roberts 2010; Bloom and Van Reenen 2010; Bloom, Eifert, Mahajan, McKenzie, and Roberts 2013).

The remainder of the paper is organized as follows. Section 2 illustrates the theoretical model that guides the empirical analysis. Section 3 provides the details of the setting under investigation, while Section 4 describe the data we use. We carry out the empirical analysis and provide the results in Section 5. Section 6 concludes.

\section{Conceptual Framework}

This section illustrates how asymmetric information and heterogeneity in input quality and worker type shape the worker's response to monetary incentives and self-selection at the workplace. Let each worker $i$ independently produce output $y_{i} \geq 0$ by combining her effort $a_{i} \geq 0$ with an input of heterogeneous quality $s_{i} \geq 0$. Output at a given moment in time is equal to

$$
y_{i}=f\left(a_{i}, s_{i}\right)+\varepsilon_{i}
$$


where $\partial^{2} f(\cdot) / \partial a_{i}^{2}<0$. Output is a concave function of worker's effort. We do not make any assumption on the complementarity or substitutability between $a_{i}$ and $s_{i}$ in production. The term $\varepsilon_{i}$ captures any unobserved residual determinants of output, identically and independently distributed across workers following a normal distribution with mean zero and variance $\sigma^{2}$.

The cost of effort is linear and equal to $C\left(a_{i}\right)=\theta_{i} a_{i}$, with $\theta_{i}>0$. The marginal cost of effort $\theta_{i}$ defines worker's type. $\theta_{i}$ is heterogeneous across workers, independently drawn from the same distribution. Each worker knows his type, perfectly observes input quality, and exerts effort. The management observes both effort $a_{i}$ and output $y_{i}$, but has no information on input quality $s_{i}$ and worker's type $\theta_{i} \cdot{ }^{1}$ Despite effort $a_{i}$ being observable, the principal cannot write a contract that specifies the optimal level of effort as that depends on unobservable input quality $s_{i}$. The asymmetry of information between the worker and the management over $s_{i}$ together with the presence of the idiosyncratic shock $\varepsilon_{i}$ generates moral hazard and the scope for incentives.

Let the wage be equal to $w_{i}$. The worker is risk averse and has a CARA utility function $u_{i}=-e^{-\eta\left(w_{i}-\theta_{i} a_{i}\right)}$, where $\eta$ is the coefficient of absolute risk aversion. Consider a contract that rewards the worker with a fixed salary plus a variable amount that depends linearly on both effort $a_{i}$ and output $y_{i}$. This wage structure matches the one observed in our empirical application and we take it as given. That is, we abstract from investigating whether this is the contract structure that maximizes the principal's payoff. Notice however that rewarding the worker in both dimensions can be optimal because the two metrics are informative of the worker's choice, but (i) vary in the amount of risk they impose on the employee, and (ii) enter the principal's payoff in different ways (Hölmstrom 1979; Baker 1992). ${ }^{2}$ In Appendix A.2, we match our empirical application by specifying the production function, and derive sufficient conditions such that the principal finds optimal to incentivize the worker on both effort $a_{i}$ and output $y_{i}$.

The wage is equal to

$$
w_{i}=f+\alpha y_{i}+(1-\alpha) a_{i}
$$

\footnotetext{
${ }^{1}$ As we explain later, in Appendix A.3 we expand the model to allow for a second unobservable effort choice in a multi-tasking setting, and derive the conditions under which we obtain the same theoretical predictions obtained here.

${ }^{2}$ A number of theoretical papers, from Holmstrom and Milgrom (1987) to Carroll (2015), show that linear contracts can be fully optimal contracts under specific conditions.
} 
where $f$ is the fixed wage component, and $\alpha$ is the relative weight attached to each performance measure. If $\alpha=0$, the worker is incentivized on effort only. If $\alpha=1$, the worker is incentivized on output only. If $0 \leq \alpha \leq 1$, the worker is incentivized on both measures.

The worker chooses the effort level $a_{i}$ that maximizes his utility, which is equivalent to the one maximizing the certainty equivalent

$$
\hat{u}_{i}=f+\alpha y_{i}+(1-\alpha) a_{i}-\theta_{i} a_{i}-\frac{\eta}{2} \alpha^{2} \sigma^{2}
$$

Taking the corresponding first order condition we get

$$
\frac{\partial f\left(s_{i}, a_{i}\right)}{\partial a_{i}}=1-\frac{1-\theta_{i}}{\alpha}
$$

Let $1>\theta_{i} \geq 1-\alpha$. Equation 4 implicitly defines the optimal effort level $a_{i}^{*}$ exerted by the worker. Since $\partial^{2} f(\cdot) / \partial a_{i}^{2}<0$, it follows that

(i) $\partial a_{i}^{*} / \partial \alpha<0$ : increasing the relative weight $\alpha$ attached to output decreases worker's effort;

(ii) $\partial a_{i}^{*} / \partial \theta_{i}<0$ : workers with higher marginal cost $\theta_{i}$ exert less effort.

At the same time, worker's response to incentives depends on the interaction of input quality $s_{i}$ and the level of effort $a_{i}$. In particular

(iii) If $\partial^{3} f\left(s_{i}, a_{i}\right) / \partial a_{i}^{2} s_{i} \geq 0$ then $\partial^{2} a_{i}^{*} / \partial \alpha \partial s_{i} \leq 0$ : an increase in $\alpha$ will decrease $a_{i}^{*}$ relatively more for workers handling inputs of higher quality $s_{i}$;

(iv) If $\partial^{3} f\left(s_{i}, a_{i}\right) / \partial a_{i}^{2} s_{i} \leq 0$ then $\partial^{2} a_{i}^{*} / \partial \alpha \partial s_{i} \geq 0$ : an increase in $\alpha$ will decrease $a_{i}^{*}$ relatively less for workers handling inputs of higher quality $s_{i}$.

The production function is concave with respect to effort. If the quality of inputs affects such concavity, it will also affect worker's response to incentives. This is because input quality changes the sensitivity of output to effort. If $\partial^{3} f\left(s_{i}, a_{i}\right) / \partial a_{i}^{2} s_{i} \geq 0$, output is less sensitive to effort at higher levels of input quality. When the salary weight attached to output increases, the 
optimal effort level falls disproportionally more for workers handling inputs of higher quality. The opposite holds if $\partial^{3} f\left(s_{i}, a_{i}\right) / \partial a_{i}^{2} s_{i} \leq 0$.

Heterogeneity in worker type also affects the response to incentives as

(v) $\partial^{2} a_{i}^{*} / \partial \alpha \partial \theta_{i}>0$ : an increase in $\alpha$ decreases effort relatively less for workers with higher marginal cost $\theta_{i}$.

The effect of changing $\alpha$ on output is ambiguous. Notice that the level of effort that maximizes output is defined implicitly by setting the right-hand side of equation 4 equal to zero. The level of $\alpha$ that maximizes output is equal to $\tilde{\alpha}=1-\theta_{i}$. It follows that if $\alpha<\tilde{\alpha}$ worker's effort is higher than the one that would maximize output: increasing $\alpha$ would decrease the level of effort and increase output. Effort and output would instead both increase if starting from $\alpha>\tilde{\alpha}$.

\subsection{Participation}

The value of $\alpha$ also affects the participation constraint, with implications for worker selfselection. Starting from the expression of the worker's certainty equivalent in equation 3 , we can take its derivative with respect to $\alpha$ and get

$$
\frac{\partial \hat{u}}{\partial \alpha}=y_{i}-a_{i}+\alpha \frac{\partial y_{i}}{\partial \alpha}+\left(1-\alpha-\theta_{i}\right) \frac{\partial a_{i}}{\partial \alpha}-\eta \alpha \sigma^{2}
$$

Since $\frac{\partial y_{i}}{\partial \alpha}=\frac{\partial f\left(s_{i}, a_{i}\right)}{\partial a_{i}} \frac{\partial a_{i}}{\partial \alpha}$ and the worker chooses the optimal effort $a_{i}^{*}$, we can replace the first order condition in equation 4 and obtain

$$
\frac{\partial \hat{u}}{\partial \alpha}=y_{i}-a_{i}^{*}-\eta \alpha \sigma^{2}
$$

Taking the derivative with respect to $\theta_{i}$, we can replace again the first order condition to get

(vi) $\partial^{2} \hat{u} / \partial \alpha \partial \theta_{i}=-\frac{1-\theta_{i}}{\alpha} \frac{\partial a_{i}}{\partial \theta_{i}}>0$ : an increase in $\alpha$ increases expected utility on the job relatively more for workers with higher marginal cost $\theta_{i}$.

Finally, utility on the job also depends on the assigned input quality: 
(vii) If $\partial^{3} f\left(s_{i}, a_{i}\right) / \partial a_{i}^{2} s_{i} \geq 0$ then $\partial^{2} a_{i} / \partial \theta_{i} \partial s_{i} \leq 0$ and $\partial^{3} \hat{u} / \partial \alpha \partial \theta_{i} \partial s_{i}=-\frac{1-\theta_{i}}{\alpha} \frac{\partial^{2} a_{i}}{\partial \theta_{i} \partial s_{i}} \geq 0$ : as $\alpha$ increases, the expected utility on the job raises differentially more for workers with higher marginal cost $\theta_{i}$ who handle inputs of higher quality $s_{i}$.

These results illustrate how, in the presence of asymmetric information over input quality and worker type, the effect of changing the relative weight attached to output in the bonus formula on worker's effort and participation decision is shaped by heterogeneity along both margins. Appendix A.3 shows that we can obtain the same predictions in a multi-tasking setting that allows for a second unobservable effort choice.

\section{The Setting}

To test these theoretical predictions, we use personnel data from a Peruvian egg producing plant (Amodio and Martinez-Carrasco 2018). This belongs to a company whose core business is egg production and sale. The company accounts for $22 \%$ of the national egg production in this period for which we have data. The plant is organized in different sectors, each one with its own management and workers, but all reporting to the same firm production manager. One sector is shown in Figure A.1 of Appendix A.1. Each sector comprises different sheds, longshaped facilities containing one to four different production units. As an example, Figure A.2 of Appendix A.1 shows a shed that hosts four production units.

Each worker is assigned to a given production unit. This is the basic unit of operation at the plant. The technology of production is independent across production units, i.e. no externalities arise among them. Each production unit is endowed with a batch of laying hens. All hens within a given batch share very similar characteristics. The batch as a whole is treated as a single input, as all hens within the batch are bought all together from a third supplier company, raised in a dedicated sector, and moved to production accordingly. When that happens, they are assigned to a specific production unit and the worker that operates it for their entire productive life. Workers exert effort along three main dimensions: egg collection and storage, hen feeding, and cleaning and maintenance of the unit facilities. Table A.1 in Appendix A.1 shows the typical 
daily schedule of a worker.

Output is measured by the number of eggs collected during the day. Mapping from our conceptual framework, output is a function of both hen characteristics or input quality and worker's effort. Hen feeding is observable by the management, which records information on the number of sacks of food distributed by the worker during the day. Effort is costly, as workers need to carry multiple $50 \mathrm{~kg}$ sacks of food a day, walking within the production unit along cages and distributing it among all hens. Importantly, the amount of food distributed is decided by the worker and varies according to input quality. Each morning, a truck arrives at the production unit and unloads a large (unbinding) number of sacks. The worker decides how many of those to distribute during the day. ${ }^{3}$

\subsection{Changing Incentives}

Workers in the firm are paid every two weeks. Their salary is equal to a fixed wage plus a bonus component that depends on worker performance as measured in a randomly chosen day within the two-week pay period. Importantly, the formula to calculate the bonus changed over time. In the first part of our sampling period, the bonus payment is calculated according to the sum of the number of sacks of food distributed by the worker and the total number of boxes of eggs collected. If this quantity exceeds a given threshold, a piece rate is awarded for each unit above the threshold. On 24 February 2012, the company adopted a new bonus formula. This is now based on the number of boxes of eggs collected only, with no weight attached to the amount of food distributed by the worker. Such quantity is multiplied by two, and a piece rate is awarded for each unit above a given threshold, with the latter being the same across the two periods and contracts.

Mapping from our conceptual framework, the total number of boxes of eggs collected is a measure of output $y_{i}$, while the number of sacks of food distributed is a measure of worker's effort $a_{i}$. The first contract is such that $\alpha=1 / 2$, and the second contract is such that $\alpha=1$.

\footnotetext{
${ }^{3}$ Production units are independent from each other and there is no scope for technological spillovers. Egg storage and manipulation is also independent across units, as each one of them is endowed with an independent warehouse for egg and food storage. The warehouses are visible in Figure A.2 of Appendix A.1, located in front of each production unit.
} 
This is the source of variation that we exploit to test the model predictions. In Appendix A.4, we show theoretically that the presence of a threshold for piece rate pay does not confound our interpretation of results as it would yield empirical predictions of opposite sign.

The change in the bonus payment structure came along with turnover in production management personnel which took place in the end of 2010. The main innovation brought by the new management was a new way of compiling and processing information on production. Their objective was to create a daily dataset on batches, workers, and their operations to be used for decision making. Following the creation of this dataset, the new management realized that workers were distributing "too much food" under the earlier incentive scheme. This speaks to the supposed inability of the firm under the previous management to correctly specify the contract that maximizes its payoff. This is hardly surprising in the context of a large firm operating in a developing country setting (Bloom, Eifert, Mahajan, McKenzie, and Roberts 2013). As we show in our empirical analysis, the implementation of the new salary scheme manages to reduce the amount of food distributed by the workers, in line with the management's expectations and goal. Our conversations with the management reveal that the rationale for the original contract is consistent with the theoretical considerations of Section 2. The objective was to recognize task heterogeneity between workers handling batches of different size. Indeed, as we also show in the Appendix A.2, the features of the implemented contract are shaped by the amount of unobserved heterogeneity and the amount of risk workers can bear.

Notice that, in our conceptual framework, we do not consider the additional incentive effect of dismissal threat. In Amodio and Martinez-Carrasco (2018), we regard and model it as a salient feature of this environment, which generates free riding and negative productivity spillovers among workers. We there use only data belonging to the period after the implementation of the new bonus formula. The dismissal policy implemented at the firm does not change throughout the entire period for which we have now data and that we consider in this paper. We can therefore abstract from this issue in both our theoretical and empirical analysis. 


\section{Data and Descriptives}

For the purpose of this study, we gained access to daily records for all production units in one sector from June 2011 to December 2012. These data cover the period from 8 months prior to 10 months following the change in the incentive scheme. We observe 94 production units in total. Across all of them, we identify 211 different hen batches. We also count 127 workers at work in the sector for at least one day.

Table A.2 in Appendix A.1 shows the summary statistics for the main variables that we use in the empirical analysis. Workers distribute 23.4 sacks of food a day on average. This quantity varies both across and within workers, with a minimum of 0.5 and a maximum of 39 . As in the model, at least part of this variation is attributable to heterogeneity in input quality. Indeed, the productivity of hens in production varies across and within production units over time. This is partially informed by the innate characteristics of the hens, which also determine how their productivity evolves with age. When the batch of hens is moved to production, productivity is initially low, then increases as hens become older, peaking and decreasing afterwards as hens reach the end of their productive life. When purchased, each batch comes with detailed information on the average number of eggs per week each hen is expected to produce at every week of its age. This measure is elaborated by the seller, and is therefore exogenous to anything specific of the plant or the worker who ends up being assigned that specific batch. ${ }^{4}$ These data are kept and analyzed exclusively by veterinaries and production managers to monitor hens' health, and taken as a loose reference point to assess the productivity of sectors. Nonetheless, we can exploit this information to derive our preferred measure of input quality. Specifically, we divide the expected weekly productivity measure by 7 to get daily productivity. As shown in Table A.2, input quality varies from 0.02 to 0.93 , with an average of 0.81 .

The total number of hens per batch is also heterogenous across and within production units over time. This is because batches can have a different size to begin with, but also because some hens die as time goes by. Importantly, when hens within a batch die they are not replaced

\footnotetext{
${ }^{4}$ In our conversations with them, production managers recognize their inability to disentangle the separate impact of the period in the dedicated raising sector (before they are moved to production) and workers' effort on productivity.
} 
with new ones: only the whole batch is replaced altogether once the remaining hens reach the end of their productive life. As a result, while we observe around 10,000 hens on average per production unit, their number varies considerably from 343 to more than 15,000. Dividing the total amount of food distributed by the number of hens, we derive the amount of food per hen that is distributed by the worker, averaging 116 grams per day.

Output is given by the number of eggs collected. Workers collect an average more than 8,000 eggs per day. This corresponds to 0.8 daily eggs per hen on average, ranging from 0 to 1 . Notice that the average matches the expected productivity or input quality measure closely. The data also provide information on the number of good, dirty, porous, and broken eggs - workers can turn a dirty egg into a good egg by cleaning it. We divide the number of eggs in each category by the total in order to derive measures of output quality. On average, $86 \%$ of the total number of eggs collected are good, which means they can directly move to the packaging stage. The remaining $14 \%$ is split between the other categories.

Finally, the data provide information on workers' daily absences. We observe for every production unit if the worker in charge was absent or not each day and a classification of the reasons behind it. Using this classification, we are able to identify unplanned absences, i.e. those that were not planned or discussed ex-ante with the management. These include unjustified absences, medical leave, or absences as a consequences of quits or undue delays. ${ }^{5}$ The frequency of absences is $4.9 \%$ in our sample, $5.4 \%$ in the period before and $4.5 \%$ in the period after the implementation of the salary change. Unplanned absences, on the other hand, occur at a rate of $2.88 \%$, being $2.79 \%$ before and $2.95 \%$ after the incentive change. 120 of the workers have been absent at least one day during the sampling period.

\section{Empirical Analysis}

Our model unambiguously predicts that effort falls when the weight attached to output in the bonus formula increases. In this setting, the amount of food distributed measures worker's effort. On 29 November 2011, the firm announced that it would implement a new salary struc-

\footnotetext{
${ }^{5}$ Anecdotical evidence suggests that many workers use medical leave as an excuse to miss a day of work.
} 
ture, changing the weight $\alpha$ attached to output from $1 / 2$ to 1 . The change was implemented on 24 February 2012.

Figure 1 shows the average amount of food distributed daily over time during the sample period. The graph shows the smoothed average together with its $95 \%$ confidence interval. The two vertical red lines correspond to the dates of announcement and implementation of the new salary scheme. The amount of food distributed is stable before the announcement, falls discontinuously on announcement and implementation dates, and then seems to stabilize again in the later period at a level that is lower than the initial one. Such fall is consistent with our model prediction. But, if all workers were fully informed about the shape of the production function, we would observe effort levels to fall only on the implementation date, and stabilize immediately at the new optimum. This pattern suggests instead that workers do not hold perfect information over the shape of the production function. The announcement of a new salary structure that puts zero weight on the amount of food distributed leads the workers to decrease the amount of effort they exert along this margin. We hypothesize that this triggered a learning process over the exact shape of the production function around the new optimum, which could explain the fall and rise in the average effort level, and its later stabilization. In another paper still work in progress, we describe and provide evidence of this learning process.

The model also predicts that, if the concavity of output with respect to effort changes with input quality, the response to a change in $\alpha$ will be differential along this dimension. Figure 2 plots the average number of eggs per hen collected by the worker against the amount of food per hen distributed on the same day. It does so separately for production units endowed with batches with input quality higher and lower than the median, where input quality is measured as expected productivity according to the information provided by the batch supplier. The graph plots the smoothed average together with its $95 \%$ confidence interval. Notice first that the productivity of high quality hens is always higher than the one of low quality hens. This is true at any given level of food intake. Second, the concavity of output with respect to effort is higher when input quality is lower. This means that output is less sensitive to changes in food intake when input quality is higher, i.e. $\partial^{3} f\left(s_{i}, a_{i}\right) / \partial a_{i}^{2} s_{i}>0$. 


\subsection{Input Quality}

The model predicts that, if higher input quality makes output less sensitive to effort, an increase in the weight attached to output in the bonus formula will decrease effort differentially more for those workers handling inputs of higher quality. We can test this hypothesis by exploiting the salary change implemented at the firm.

Figure 3 plots the average food distributed by the worker handling inputs of different quality. Specifically, we take residuals from a regression of the total number of sacks of food distributed over the total number of hens and worker fixed effects, and plot its smoothed average against input quality. The graph shows the smoothed average together with its $95 \%$ confidence interval, and separately for observations belonging to the period before and after the implementation of the new incentive scheme. First, consistent with Figure 1, evidence shows that the average amount of food distributed is lower after the change in the bonus formula. This is true for any given level of input quality. Second, Figure 3 shows that the difference between the two periods is larger when input quality is higher, which is what the model predicts.

Figure 4 plots the smoothed average of residual food distributed over time, and separately for production units endowed with batches with input quality higher and lower than the median. As in Figure 1, the two vertical red lines correspond to the dates of announcement and implementation of the new salary scheme. Figure 4 shows that the positive difference in average food distributed between production units endowed with batches of different input quality shrinks discontinuously after the announcement of the new incentive scheme. This is consistent with Figure 3 and what the model predicts: when the salary weight attached to output increases, feeding effort falls disproportionally more for workers handling inputs of higher quality.

We investigate these patterns more systematically by implementing the following differencein-differences regression specification

$$
a_{i g t}=\alpha+\beta \text { post }_{t}+\gamma s_{i g t}+\delta s_{i g t} \times \text { post }_{t}+\epsilon_{i g t}
$$

where $a_{i g t}$ is the total amount of food distributed by worker $i$ operating a production unit in 
shed $g$ on day $t$, the variable post $t_{t}$ is a dummy equal to one for all observations belonging to the period following the implementation of the new incentive scheme, and $s_{i g t}$ is a dummy equal to one if input quality is higher than the median. To net out differences in input quantity, we include the total number of hens as a control in all specifications. The term $\epsilon_{i g t}$ captures any residual determinant of the worker's choice. We allow those to be correlated both in time and space by clustering standard errors along the two dimensions of shed and day.

Our coefficient of interest is $\delta$, which captures whether the response to the change in the bonus formula is differential according to input quality. Since $\partial^{3} f\left(s_{i}, a_{i}\right) / \partial a_{i}^{2} s_{i}>0$, the model predicts $\delta<0$. Identification requires that, in the absence of a change in the bonus formula, the amount of food distributed would have not changed differentially across workers handling inputs of different quality. Figure 4 supports this assumption by showing that the difference in food distributed across production units endowed with hens of different quality does not change systematically over time in the period prior to the announcement of the new salary scheme. Moreover, no change in technology or batch assignment rule occurred in the period of announcement or implementation, so that there are no immediate reasons for questioning the validity of the identifying assumption. Recall also that our measure of input quality is obtained from the batch supplier company, and is therefore exogenous to anything specific of the production process, including the workers who are ultimately assigned the batch input. Also, we later show how variation in input quality does not overlap with variation in worker type.

Table 1 reports the corresponding coefficient estimates. Consistent with Figure 1, the negative and significant coefficient of the post $t_{t}$ dummy indicates that the amount food distributed falls after the implementation of the new salary scheme. The coefficient of the interaction variable is negative and highly significant: as the new contract puts a higher weight on output in the bonus formula, effort decreases differentially more for those workers handling inputs of higher quality. The coefficient remains negative, significant at the $1 \%$ level, and stable in magnitude as we progressively include worker, day, and shed fixed effects in columns 2 to 4 . In column 5, we also include the interaction between input quality and a dummy equal to one for those 
observations belonging to the period between the announcement and the implementation of the new bonus formula. Although both coefficients of the interaction variables are negative, only the one corresponding to the period after implementation is significantly different from zero at the $1 \%$ level. Overall, these results provide evidence of a systematically differential response to incentive change along the margin of input quality in the direction that the model predicts.

\subsection{Worker Type}

The model also predicts that an increase in the weight attached to output in the bonus formula will decrease effort differentially less for workers with higher marginal cost of effort or worker type $\theta_{i}$. To test this hypothesis, we first obtain a proxy for worker type as follows. Workers with a higher marginal cost of effort distribute systematically less food. We thus restrict the sample to those observations belonging to the period before the announcement of the new salary scheme, and regress the number of sacks of food distributed over the proxy for input quality, the total number of hens, day, batch, and worker fixed effects. Figure 5 shows the distribution of the estimated fixed effects $\hat{\phi}_{i}$ that we obtain from this exercise. We regard a higher $\hat{\phi}_{i}$ as being associated with a lower marginal cost of effort $\theta_{i}$.

Similarly to Figure 4, Figure 6 plots the smoothed average of residual food distributed over

time, and separately for production units operated by workers with $\hat{\phi}_{i}$ higher and lower than the median. The residual is obtained from a regression of the total number of sacks of food distributed over the total number of hens and the measure of input quality. The Figure shows that the positive difference in average food distributed between production units operated by workers of different type shrinks after the announcement of the new incentive scheme, suggesting that workers with higher permanent productivity decrease their feeding effort differentially more after the implementation of the new incentive scheme.

We then implement the following regression specification

$$
a_{i g t}=\hat{\phi}_{i}+\beta \text { post }_{t}+\gamma s_{i g t}+\delta \hat{\phi}_{i} \times \text { post }_{t}+\mu_{i g t}
$$

where $\hat{\phi}_{i}$ is the variable capturing the estimated worker fixed effects obtained as explained 
above, and the rest of the regressors are specified as in equation 7. Also in this case, the term $\mu_{\text {igt }}$ captures any residual variation in the amount of food distributed, that we allow to be correlated within shed and day. The model predicts $\delta<0$ : workers with higher $\hat{\phi}_{i}$ (lower $\theta_{i}$ ) should decrease their amount of effort differentially more after the implementation of the new bonus formula. Identification requires that, in the absence of a change in the bonus formula, the amount of food distributed would have not changed differentially across workers who are heterogeneous in their marginal cost of effort as proxied by $\hat{\phi}_{i}$. Figure 6 supports this assumption by showing that the difference in food distributed across production units operated by workers of different type does not change systematically over time in the period prior to the announcement of the new salary scheme.

Table 2 shows the corresponding coefficient estimates. The estimated $\delta$ is negative and significant at the $1 \%$ level, consistent with the model prediction. Starting with column 2, we do as in Table 1 and progressively include worker, day, and shed fixed effects. In column 5, we also include the interaction between input quality and a dummy equal to one for those observations belonging to the period between the announcement and the implementation of the new bonus formula. The estimated $\delta$ remains negative and highly significant, its magnitude increasing as we move from column 2 to $5 .^{6}$

Evidence from Tables 1 and 2 is consistent with the model predictions. Workers handling inputs of higher quality decrease their feeding effort differentially more after the implementation of the new incentive scheme. The same is true for workers with higher permanent productivity, i.e. lower marginal cost of effort. A natural question is whether heterogeneity along these two dimensions overlaps and to what extent. In principle, there is no reason to believe that this is the case. Hen productivity evolves with age, and input quality varies both across and within production units over time. This means that, conditional to the assignment of a given batch of hens to a production unit and the worker that operates it, input quality keeps changing over time as hens become older. We nonetheless address this concern by combining the regres-

\footnotetext{
${ }^{6}$ The worker fixed effects $\hat{\phi}_{i}$ and their interaction that we include in equation 8 are estimated, which could invalidate the coefficient standard errors reported in Table 2. We take this into account by implementing a bootstrapping procedure and estimating the model coefficients over 500 random samples with replacement. Table A.3 in Appendix A.1 reports the corresponding coefficient estimates and empirical standard errors, showing very similar results.
} 
sion specifications in equation 7 and 8 , and including all variables and interactions together as regressors. Table 3 reports the corresponding coefficient estimates. ${ }^{7}$ The coefficients of the interaction variables are very similar to those obtained separately and reported in Tables 1 and 2. This indicates that the variability in worker types does not overlap with the one in input quality. Overall, evidence shows that heterogeneity along both dimensions of input quality and worker type shapes workers' response to incentives, and it does so in the way predicted by the model we presented in Section 2.

\subsection{Output, Wages, and Profits}

The model in Section 2 delivers ambiguous predictions on the effect of a change in the weight attached to output in the bonus formula on output itself. We empirically estimate this effect by implementing the same specification that we used to produce Table 3, but replacing total output measured by the total amount of egg boxes collected as dependent variable. Each box contains 360 eggs. Table 4 shows the corresponding results. Not surprisingly, higher input quality is associated with higher output. Yet, we do not find any other systematic pattern. While the estimated coefficient for post $_{t}$ in column 1 suggests that output fell significantly when the new bonus formula was implemented, this result is not robust to the inclusion of the full set of worker fixed effects. In contrast with the previous findings, we find no evidence of a differential effect on output according to input quality or worker type. ${ }^{8}$

Evidence shows that the new scheme achieved to reduce the amount of food that workers distribute on each day, with no discernible negative and significant effect on output. Food is a costly input for the firm, but the overall effect of the incentive change on profits will also depend on whether the firm pays higher or lower bonuses after its implementation. To get at that, we derive a proxy bonus $_{i g t}$ for the bonus paid to worker $i$ operating a production unit in shed $g$ on day $t$. We do so by exploiting the available information on eggs collected, sacks of food

\footnotetext{
${ }^{7}$ Table A.4 in Appendix A.1 shows that results are unchanged when we use the continuous measure of input quality $s_{i g t}$ rather than a dummy for whether input quality is above the sample median.

${ }^{8}$ Table A.5 in Appendix A.1 provides some evidence of a significant differential reduction in output along the margin of input quality in the period between the announcement and the implementation of the new payment scheme. Yet, as shown already in column 5 of Table 4, the corresponding estimate is no longer statistically significant at the standard levels when including the full set of worker, day, and shed fixed effects as controls.
} 
distributed, and the bonus formula before and after the incentive change.

Before the change, the bonus payment is calculated as a piece rate that is proportional to the sum of the number of sacks of food distributed by the worker and the total number of boxes of eggs collected. After the change, the bonus is a piece rate that increases with twice the number of boxes of eggs collected only. Knowing that each box contains 360 eggs, for the period before the change we calculate

$$
\text { bonus }_{i g t}=\frac{1}{2}\left(\frac{y_{i g t}}{360}+a_{i g t}\right)
$$

where $y_{i g t}$ is the total number of eggs collected by the worker, and $a_{i g t}$ is the amount of sacks of food distributed. For the period after the change, we calculate

$$
\text { bonus }_{i g t}=\frac{y_{\text {igt }}}{360}
$$

We then implement the same regression specification that we used to produce the results in Table 3 and Table 4, but replacing bonus $_{\text {igt }}$ as dependent variable. Remember that both the piece-rate parameter and the threshold for incentive pay do not change before and after the change in the bonus formula. Incorporating those would only change the scale and mean of the bonus $_{i g t}$ variable, with no impact on the sign and significance of coefficient estimates.

Table 5 shows the corresponding results. In the first four columns, the coefficients of the interaction of the dummy for high input quality and the post-implementation dummy are positive and significantly different from zero. In contrast, the coefficients of the interaction with the estimated worker fixed effects are negative, but insignificant at standard levels across all specifications. As in the previous tables, in column 5 we include as additional regressor the interactions with a dummy equal to one for those observations belonging to the period between the announcement and the implementation of the new salary scheme. The differential increase in the bonus paid to the workers handling high quality inputs is no longer significant when allowing for a differential effect in the transition period. Yet, the bonus paid to workers with a higher $\hat{\phi}_{i}\left(\right.$ lower $\left.\theta_{i}\right)$ is differentially and significantly lower after the implementation of the new bonus 
formula respect to the period pre-announcement. ${ }^{9}$ Table 3 and 4 show that both categories of workers - those handling high quality inputs and those with high permanent productivity distribute differentially less food, with no differential effect on output. Given that the prices of eggs, food, and other inputs are not differential across workers according to their type or the quality of assigned inputs, these results indicate that the change in the bonus formula allows the firm to make differentially higher profits from workers handling inputs of higher quality and from those having a lower marginal cost of effort or higher permanent productivity.

The previous results do not consider the possibility that the incentive change also affects the quality of output. We test this hypothesis by replacing the corresponding output quality measures as dependent variable and estimating the coefficients from the same regression specification as above. For each quality measure, Table 6 reports the main coefficient estimates from regressions without and with day and shed fixed effects. Evidence shows that the fraction of good eggs decreases differentially and significantly for workers handling inputs of higher quality, while it increases differentially for workers with higher estimated permanent productivity. This pattern is reversed when considering the fraction of broken eggs. The coefficients of interest are instead insignificant when considering the fraction of dirty and porous eggs. Table A.7 in Appendix A.1 allows for a differential effect in the period between announcement and implementation. The fraction of broken eggs still significantly increases for workers handling inputs of higher quality, but the fraction of good eggs does not change differentially. On the contrary, all measures indicates that output quality increases differentially for workers with higher permanent productivity. We interpret these results altogether as showing that output quality decreases differentially for workers handling high quality inputs. To the extent to which output quality matters for revenues, this may undermine the differentially higher profitability of the incentive change for this category of workers. In contrast, output quality increases differentially for workers having a lower marginal cost of effort. Together with the previous findings, this further supports the hypothesis that the firm makes differentially higher profits from workers with higher permanent productivity after the incentive change.

\footnotetext{
${ }^{9}$ Table A.6 shows that these results are unchanged when allowing for a differential effect in the period between announcement and implementation of the new contract.
} 
Taken altogether, evidence shows that asymmetric information and heterogeneity along the two margins of input quality and worker type matters not only in determining worker's effort response to incentives, but also the effectiveness of the latter in increasing firm profits.

\subsection{Absenteeism and Retention}

We now study the effect of the incentive change on worker self-selection. The model predicts that an increase in the weight attached to output in the bonus formula will increase expected utility on the job relatively more for workers with higher marginal cost effort $\theta_{i}$. This has implication for worker absenteeism and retention. In particular, given no change in the outside option of workers, we should expect absenteeism and quits to increase differentially among workers with lower marginal cost of effort, i.e. higher permanent productivity.

We test this prediction by implement a logistic hazard model and study the relative odds of the probability $h_{i t}$ that the worker $i$ is absent on day $t$ as defined by

$$
\frac{h_{i t}}{1-h_{i t}}=\exp \left\{\kappa_{t}+\alpha h_{i}+\beta \text { post }_{t}\right\}
$$

where $h_{i}$ is a dummy equal to one if the estimated worker fixed effect $\hat{\phi}_{i}$ estimated above is higher than the median, and post $t_{t}$ is a dummy equal to one for all observations belonging to the period following the implementation of the new incentive scheme. $\kappa_{t}$ captures the baseline odds of being absent, which we allow to vary with time by including the full set of month fixed effects. In other words, we let the baseline probability of absence to vary flexibly across months.

Similarly, we study the relative odds of the probability $q_{i}(t)$ that worker $i$ 's employment relationship terminates after $t$ days on the job as defined by

$$
\frac{q_{i}(t)}{1-q_{i}(t)}=\exp \left\{\gamma_{t}+\alpha h_{i}+\beta \text { post }_{t}\right\}
$$

where $t$ measures tenure on the job and is defined as days since the worker first appears in the data. We let $\gamma_{t}=\delta \ln t$, and we estimate $\delta$ together with $\alpha$ and $\beta$ in order to let the baseline 
hazard of termination on day $t$ to increase or decrease monotonically with tenure depending on the value of $\delta .^{10}$

We estimated both models using maximum likelihood, and derive odds ratios before the announcement and after the incentive change for workers with fixed effects below and above the median. Table 7 reports the estimated odds ratios and their difference-in-differences across different specifications. In column 1, the dependent variable is a dummy equal to one if the worker is absent, while in column 2 we consider only unplanned absences. We regard the latter as more apt to capture worker's unilateral decisions while the former includes absences because of vacations, special internal appointments inside the firm, etc. Column 3 reports the results on employment termination.

The model predicts that absenteeism and quits increase differentially after the incentive change among workers with lower marginal cost of effort (higher $\psi_{i}$ ). The evidence in Table 7 supports this hypothesis as it shows that the odds of unplanned absences are differentially and significantly higher for highly productive workers after the incentive change. The same is true for the probability of employment termination. This indicates that the incentive change impacts worker absenteeism, retention, and self-selection as the model predicts.

Finally, we test whether these effects are differential according to input quality. Since output is less sensitive to changes in food intake when input quality is higher $-\partial^{3} f\left(s_{i}, a_{i}\right) / \partial a_{i}^{2} s_{i}>0$ - the model predicts that the differential positive effect on absenteeism and negative effect on retention of highly productive workers should be larger when they handle inputs of higher quality. We thus add input quality as additional determinant of absenteeism and termination in the models of equation 11 and 12 respectively. Table 8 reports the estimated odds ratios and the triple difference estimates of interest. The differential positive effect of the incentive change on the absenteeism of highly productive workers is significantly larger for those handling inputs of higher quality, consistent with the model prediction. We do not find instead input quality to matter differentially for the incidence of quits. This is not surprising considering that input quality - and thus worker's expected utility - changes over time. It therefore makes sense that

\footnotetext{
${ }^{10}$ Specifically, with $\gamma_{t}=\delta \ln t$ we let $\frac{q(t)}{1-q(t)}=t^{\delta}$ and $q(t)=\frac{t^{\delta}}{1+t^{\delta}}$.
} 
it will affect absenteeism, but not necessarily the permanent decision of quitting the job.

\section{Conclusions}

In many workplaces, the productivity of workers is at least partially determined by the quality of assigned inputs. This paper shows that imperfect information on input and worker heterogeneity shapes the response to incentives and self-selection at the workplace. Using personnel data from an egg production plant in rural Peru, we exploit the variation induced by a change in the salary bonus formula combined with information on inputs and output to show that heterogeneity in input quality is associated with a differential change in worker's effort after the implementation of the new pay regime. Workers with higher permanent productivity also react differentially more to the change in incentives. The firm makes differentially higher profits from these workers, but this is costly in terms of absenteeism and retention: high productivity workers are differentially more likely to skip a day of work without consent and to quit altogether after the change is implemented.

Our study highlights how information asymmetries between workers and managers over production inputs determine the effectiveness of incentive pay in eliciting workers' effort and raising firm profits. We show that both channels of incentive and self-selection effects are affected. Our findings have clear implications for the design and implementation of performance pay schemes: the impact of one given change may be very different depending on the amount of input heterogeneity and whether information on such heterogeneity is shared by workers and managers alike. Above and beyond the static response that we analyze in this paper, we hypothesize that these same issues affect the dynamics of workers' response to changing incentives. Figure 1 provides some evidence of a dynamic adjustment process. In future research, we plan to characterize this process formally with a theoretical model and validate its empirical content. 


\section{References}

Adhvaryu, A., N. Kala, and A. Nyshadham (2019). Management and Shocks to Worker Productivity. mimeo.

Adhvaryu, A., A. Nyshadham, and J. Tamayo (2019). Managerial Quality and Productivity Dynamics. mimeo.

Amodio, F. and M. A. Martinez-Carrasco (2018). Input Allocation, Workforce Management and Productivity Spillovers: Evidence from Personnel Data. Review of Economic Studies 85(4), 1937-1970.

Atkin, D., A. Chaudhry, S. Chaudry, A. K. Khandelwal, and E. Verhoogen (2017). Organizational Barriers to Technology Adoption: Evidence from Soccer-Ball Producers in Pakistan. The Quarterly Journal of Economics 132(3), 1101-1164.

Baker, G. P. (1992). Incentive Contracts and Performance Measurement. Journal of Political Economy 100(3), 598-614.

Bandiera, O., I. Barankay, and I. Rasul (2010). Social incentives in the workplace. The Review of Economic Studies 77(2), 417-458.

Black, S. E. and L. M. Lynch (2001). How to compete: The impact of workplace practices and information technology on productivity. The Review of Economics and Statistics 83(3), $434-445$.

Bloom, N., B. Eifert, A. Mahajan, D. McKenzie, and J. Roberts (2013). Does Management Matter? Evidence from India. The Quarterly Journal of Economics 128(1), 1-51.

Bloom, N., A. Mahajan, D. McKenzie, and J. Roberts (2010). Why Do Firms in Developing Countries Have Low Productivity? American Economic Review: Papers \& Proceedings 100(2), 619-23.

Bloom, N. and J. Van Reenen (2007). Measuring and Explaining Management Practices Across Firms and Countries. The Quarterly Journal of Economics 122(4), 1351-1408. 
Bloom, N. and J. Van Reenen (2010). Why Do Management Practices Differ across Firms and Countries? Journal of Economic Perspectives 24(1), 203-24.

Carroll, G. (2015). Robustness and linear contracts. American Economic Review 105(2), 53663.

Guiteras, R. P. and B. K. Jack (2018). Productivity in piece-rate labor markets: Evidence from rural malawi. Journal of Development Economics 131, 42 - 61.

Hjort, J. (2014). Ethnic divisions and production in firms. The Quarterly Journal of Economics 129(4), 1899-1946.

Hölmstrom, B. (1979). Moral Hazard and Observability. The Bell Journal of Economics 10(1), 74-91.

Holmstrom, B. and P. Milgrom (1987). Aggregation and linearity in the provision of intertemporal incentives. Econometrica 55(2), 303-328.

Jayaraman, R., D. Ray, and F. de Véricourt (2016). Anatomy of a contract change. American Economic Review 106(2), 316-58.

Kaur, S., M. Kremer, and S. Mullainathan (2015). Self-control at work. Journal of Political Economy 123(6), 1227-1277.

Kim, H. B., S. Kim, and T. T. Kim (2019). The role of career and wage incentives in labor productivity: Evidence from a two-stage field experiment in malawi. The Review of Economics and Statistics $0(\mathrm{ja}), 1-45$.

Lazear, E. P. (2000). Performance pay and productivity. American Economic Review 90(5), $1346-1361$.

Menzel, A. (2019). Knowledge Exchange and Productivity Spill-overs in Bangladeshi Garment Factories. mimeo.

Prendergast, C. (1999). The provision of incentives in firms. Journal of Economic Literature 37(1), 7-63. 


\section{Tables and Figures}

Table 1: Incentive Change and Input Quality

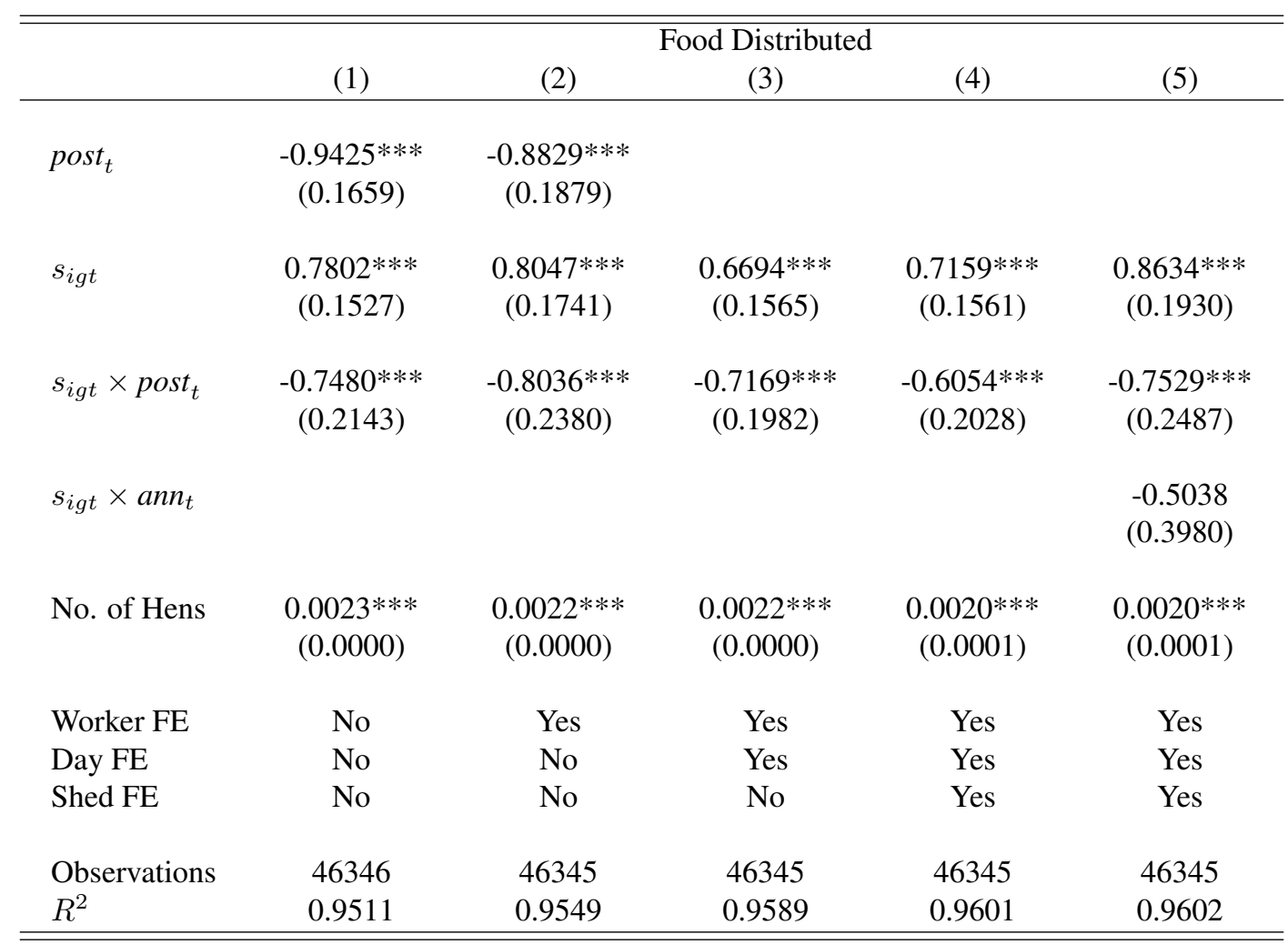

Notes. (* p-value $<0.1 ; * *$ p-value $<0.05$; *** p-value $<0.01)$ Two-way clustered standard errors, with residuals grouped along both shed and day. Dependent variable is the amount of food distributed by the worker on a given day as measured by the number of $50 \mathrm{~kg}$ sacks distributed. $s_{i b t}$ is a dummy equal to one if input quality is higher than the median. post $t_{t}$ is a dummy equal to one for all observations belonging to the period following the implementation of the new incentive scheme. $a n n_{t}$ is a dummy equal to one for all observations belonging to the period between the announcement and the implementation of the new scheme. 
Table 2: Incentive Change and Worker Types

\begin{tabular}{|c|c|c|c|c|c|}
\hline & (1) & (2) & $\begin{array}{l}\text { ood Distribut } \\
\text { (3) }\end{array}$ & (4) & (5) \\
\hline post $_{t}$ & $\begin{array}{c}-1.6056 * * * \\
(0.1629)\end{array}$ & $\begin{array}{c}-1.5273 * * * \\
(0.2193)\end{array}$ & & & \\
\hline$\hat{\phi}_{i}$ & $\begin{array}{c}0.0856 * * * \\
(0.0225)\end{array}$ & & & & \\
\hline$\hat{\phi}_{i} \times$ post $_{t}$ & $\begin{array}{c}-0.0736 * * * \\
(0.0227)\end{array}$ & $\begin{array}{c}-0.0678 * * \\
(0.0292)\end{array}$ & $\begin{array}{c}-0.0944 * * * \\
(0.0266)\end{array}$ & $\begin{array}{c}-0.1104 * * * \\
(0.0296)\end{array}$ & $\begin{array}{c}-0.1474 * * * \\
(0.0328)\end{array}$ \\
\hline$\hat{\phi}_{i} \times a n n_{t}$ & & & & & $\begin{array}{c}-0.0965 * \\
(0.0544)\end{array}$ \\
\hline$s_{i g t}$ & $\begin{array}{c}0.3812 * * * \\
(0.1192)\end{array}$ & $\begin{array}{c}0.3711 * * * \\
(0.1244)\end{array}$ & $\begin{array}{c}0.2787 * * \\
(0.1069)\end{array}$ & $\begin{array}{c}0.3840 * * * \\
(0.1090)\end{array}$ & $\begin{array}{c}0.3870 * * * \\
(0.1085)\end{array}$ \\
\hline No. of Hens & $\begin{array}{c}0.0023 * * * \\
(0.0000)\end{array}$ & $\begin{array}{c}0.0022 * * * \\
(0.0000)\end{array}$ & $\begin{array}{c}0.0022 * * * \\
(0.0000)\end{array}$ & $\begin{array}{c}0.0020 * * * \\
(0.0001)\end{array}$ & $\begin{array}{c}0.0020 * * * \\
(0.0001)\end{array}$ \\
\hline Worker FE & No & Yes & Yes & Yes & Yes \\
\hline Day FE & No & No & Yes & Yes & Yes \\
\hline Shed FE & No & No & No & Yes & Yes \\
\hline Observations & 46346 & 46345 & 46345 & 46345 & 46345 \\
\hline$R^{2}$ & 0.9511 & 0.9546 & 0.9588 & 0.9602 & 0.9603 \\
\hline
\end{tabular}

Notes. ( $*$ p-value $<0.1 ; * *$ p-value $<0.05$; *** p-value $<0.01)$ Two-way clustered standard errors, with residuals grouped along both shed and day. Dependent variable is the amount of food distributed by the worker on a given day as measured by the number of $50 \mathrm{~kg}$ sacks distributed. $s_{i b t}$ is a dummy equal to one if input quality is higher than the median. $\hat{\phi}_{i}$ is a variable equal to the estimated worker fixed effects from a regression of the number of sacks of food distributed over the proxy for input quality, the total number of hens, day, batch, and worker fixed effects, estimated over the subsample belonging to the period before the announcement of the change in the bonus formula. post $t_{t}$ is a dummy equal to one for all observations belonging to the period following the implementation of the new incentive scheme. ann $t$ is a dummy equal to one for all observations belonging to the period between the announcement and the implementation of the new scheme. 
Table 3: Incentive Change, Input Quality and Worker Types

\begin{tabular}{|c|c|c|c|c|c|}
\hline & (1) & $(2)$ & $\begin{array}{l}\text { (3) } \\
\text { (3) }\end{array}$ & (4) & $(5)$ \\
\hline post $_{t}$ & $\begin{array}{c}-1.2477 * * * \\
(0.2038)\end{array}$ & $\begin{array}{c}-1.1598 * * * \\
(0.2472)\end{array}$ & & & \\
\hline$s_{i g t}$ & $\begin{array}{c}0.7712 * * * \\
(0.1480)\end{array}$ & $\begin{array}{c}0.8118 * * * \\
(0.1747)\end{array}$ & $\begin{array}{c}0.6742 * * * \\
(0.1551)\end{array}$ & $\begin{array}{c}0.7203 * * * \\
(0.1540)\end{array}$ & $\begin{array}{c}0.8715 * * * \\
(0.1797)\end{array}$ \\
\hline$\hat{\phi}_{i}$ & $\begin{array}{c}0.0830 * * * \\
(0.0226)\end{array}$ & & & & \\
\hline$s_{i g t} \times$ post $_{t}$ & $\begin{array}{c}-0.7264 * * * \\
(0.2103)\end{array}$ & $\begin{array}{c}-0.8151 * * * \\
(0.2402)\end{array}$ & $\begin{array}{c}-0.7273 * * * \\
(0.1997)\end{array}$ & $\begin{array}{c}-0.6197 * * * \\
(0.2061)\end{array}$ & $\begin{array}{c}-0.7740 * * * \\
(0.2397)\end{array}$ \\
\hline$\hat{\phi}_{i} \times$ post $_{t}$ & $\begin{array}{c}-0.0720 * * * \\
(0.0227)\end{array}$ & $\begin{array}{c}-0.0712 * * \\
(0.0292)\end{array}$ & $\begin{array}{c}-0.0964 * * * \\
(0.0265)\end{array}$ & $\begin{array}{c}-0.1124 * * * \\
(0.0299)\end{array}$ & $\begin{array}{c}-0.1504 * * * \\
(0.0307)\end{array}$ \\
\hline$s_{i g t} \times a n n_{t}$ & & & & & $\begin{array}{l}-0.4802 \\
(0.3804)\end{array}$ \\
\hline$\hat{\phi}_{i} \times a n n_{t}$ & & & & & $\begin{array}{l}-0.0968 * \\
(0.0527)\end{array}$ \\
\hline No. of Hens & $\begin{array}{c}0.0023^{* * * *} \\
(0.0000)\end{array}$ & $\begin{array}{c}0.0022 * * * \\
(0.0000)\end{array}$ & $\begin{array}{c}0.0022 * * * \\
(0.0000)\end{array}$ & $\begin{array}{c}0.0020 * * * \\
(0.0001)\end{array}$ & $\begin{array}{c}0.0020 * * * \\
(0.0001)\end{array}$ \\
\hline Worker FE & No & Yes & Yes & Yes & Yes \\
\hline Day FE & No & No & Yes & Yes & Yes \\
\hline Shed FE & No & No & No & Yes & Yes \\
\hline Observations & 46346 & 46345 & 46345 & 46345 & 46345 \\
\hline$R^{2}$ & 0.9515 & 0.9550 & 0.9592 & 0.9604 & 0.9606 \\
\hline
\end{tabular}

Notes. (* p-value $<0.1 ; * *$ p-value $<0.05 ; * * *$ p-value $<0.01)$ Two-way clustered standard errors, with residuals grouped along both shed and day. Dependent variable is the amount of food distributed by the worker on a given day as measured by the number of $50 \mathrm{~kg}$ sacks distributed. $s_{i b t}$ is a dummy equal to one if input quality is higher than the median. $\hat{\phi}_{i}$ is a variable equal to the estimated worker fixed effects from a regression of the number of sacks of food distributed over the proxy for input quality, the total number of hens, day, batch, and worker fixed effects, estimated over the subsample belonging to the period before the announcement of the change in the bonus formula. post $t_{t}$ is a dummy equal to one for all observations belonging to the period following the implementation of the new incentive scheme. ann $t$ is a dummy equal to one for all observations belonging to the period between the announcement and the implementation of the new scheme. 
Table 4: Incentive Change and Output

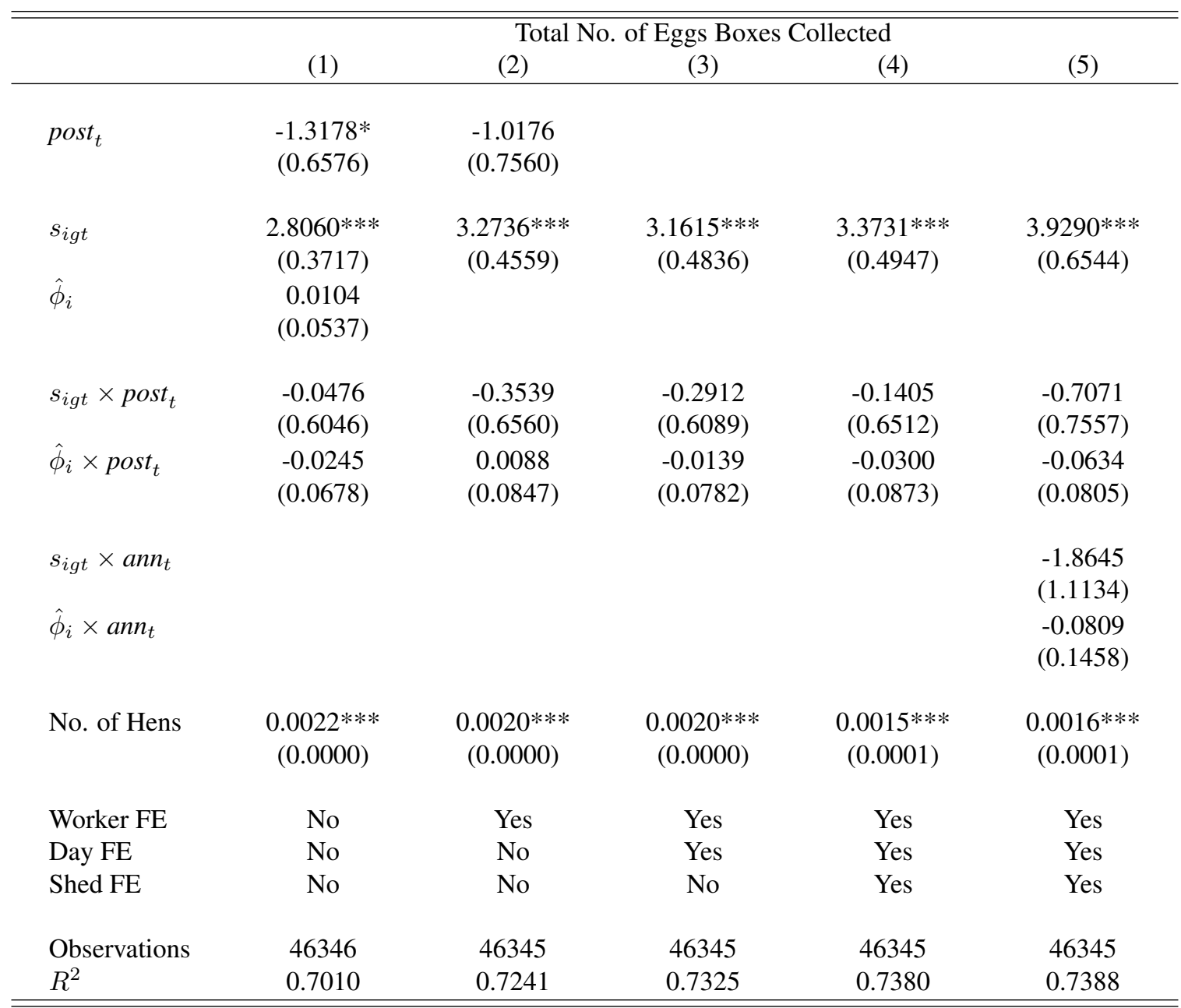

Notes. (* p-value $<0.1 ; * *$ p-value $<0.05 ; * * *$ p-value $<0.01)$ Two-way clustered standard errors, with residuals grouped along both shed and day. Dependent variable is total output as measured by the total amount of eggs boxes collected by the worker on a given day. Eggs boxes contain 360 eggs. $s_{i b t}$ is a dummy equal to one if input quality is higher than the median. $\hat{\phi}_{i}$ is a variable equal to the estimated worker fixed effects from a regression of the number of sacks of food distributed over the proxy for input quality, the total number of hens, day, batch, and worker fixed effects, estimated over the subsample belonging to the period before the announcement of the change in the bonus formula. post $t_{t}$ is a dummy equal to one for all observations belonging to the period following the implementation of the new incentive scheme. 
Table 5: Incentive Change and Bonus Paid

\begin{tabular}{|c|c|c|c|c|c|}
\hline & \multicolumn{5}{|c|}{ Bonus Paid (derived) } \\
\hline & $(1)$ & $(2)$ & (3) & (4) & (5) \\
\hline post $_{t}$ & $\begin{array}{c}-2.4269 * * * \\
(0.4948)\end{array}$ & $\begin{array}{c}-2.1914 * * * \\
(0.5905)\end{array}$ & & & \\
\hline$s_{i g t}$ & $\begin{array}{c}1.7940 * * * \\
(0.2435)\end{array}$ & $\begin{array}{c}2.0408 * * * \\
(0.3334)\end{array}$ & $\begin{array}{c}1.9075 * * * \\
(0.3441)\end{array}$ & $\begin{array}{c}2.0491 * * * \\
(0.3480)\end{array}$ & $\begin{array}{c}2.4370 * * * \\
(0.4332)\end{array}$ \\
\hline$\hat{\phi}_{i}$ & $\begin{array}{c}0.0601 \\
(0.0390)\end{array}$ & & & & \\
\hline$s_{i g t} \times$ post $_{t}$ & $\begin{array}{l}0.9531 * \\
(0.5040)\end{array}$ & $\begin{array}{c}0.8689 \\
(0.5564)\end{array}$ & $\begin{array}{l}0.9532 * \\
(0.5052)\end{array}$ & $\begin{array}{l}1.1361 * * \\
(0.5392)\end{array}$ & $\begin{array}{c}0.7356 \\
(0.5904)\end{array}$ \\
\hline$\hat{\phi}_{i} \times$ post $_{t}$ & $\begin{array}{l}-0.0809 \\
(0.0538)\end{array}$ & $\begin{array}{l}-0.0467 \\
(0.0659)\end{array}$ & $\begin{array}{l}-0.0701 \\
(0.0609)\end{array}$ & $\begin{array}{l}-0.0871 \\
(0.0681)\end{array}$ & $\begin{array}{l}-0.1183 * \\
(0.0623)\end{array}$ \\
\hline$s_{i g t} \times a n n_{t}$ & & & & & $\begin{array}{c}-1.2901 * \\
(0.7382)\end{array}$ \\
\hline$\hat{\phi}_{i} \times a n n_{t}$ & & & & & $\begin{array}{l}-0.0770 \\
(0.0976)\end{array}$ \\
\hline No. of Hens & $\begin{array}{c}0.0022 * * * \\
(0.0000)\end{array}$ & $\begin{array}{c}0.0020 * * * \\
(0.0000)\end{array}$ & $\begin{array}{c}0.0020 * * * \\
(0.0000)\end{array}$ & $\begin{array}{c}0.0016^{* * * *} \\
(0.0001)\end{array}$ & $\begin{array}{c}0.0017 * * * \\
(0.0001)\end{array}$ \\
\hline Worker FE & No & Yes & Yes & Yes & Yes \\
\hline Day FE & No & No & Yes & Yes & Yes \\
\hline Shed FE & No & No & No & Yes & Yes \\
\hline Observations & 46346 & 46345 & 46345 & 46345 & 46345 \\
\hline$R^{2}$ & 0.7555 & 0.7740 & 0.7823 & 0.7864 & 0.7868 \\
\hline
\end{tabular}

Notes. (* p-value $<0.1$; ** p-value $<0.05$; *** p-value $<0.01$ ) Two-way clustered standard errors, with residuals grouped along both shed and day. Sample is restricted to those observations belonging to the period before announcement and after implementation of the new incentive scheme. Dependent variable is a proxy for the bonus paid to workers derived using the number of eggs collected, the total amount of sacks of food distributed, and the bonus formula before and after the incentive change, as explained in Section 5.3. $s_{i b t}$ is a dummy equal to one if input quality is higher than the median. $\hat{\phi}_{i}$ is a variable equal to the estimated worker fixed effects from a regression of the number of sacks of food distributed over the proxy for input quality, the total number of hens, day, batch, and worker fixed effects, estimated over the subsample belonging to the period before the announcement of the change in the bonus formula. post $t$ is a dummy equal to one for all observations belonging to the period following the implementation of the new incentive scheme. 


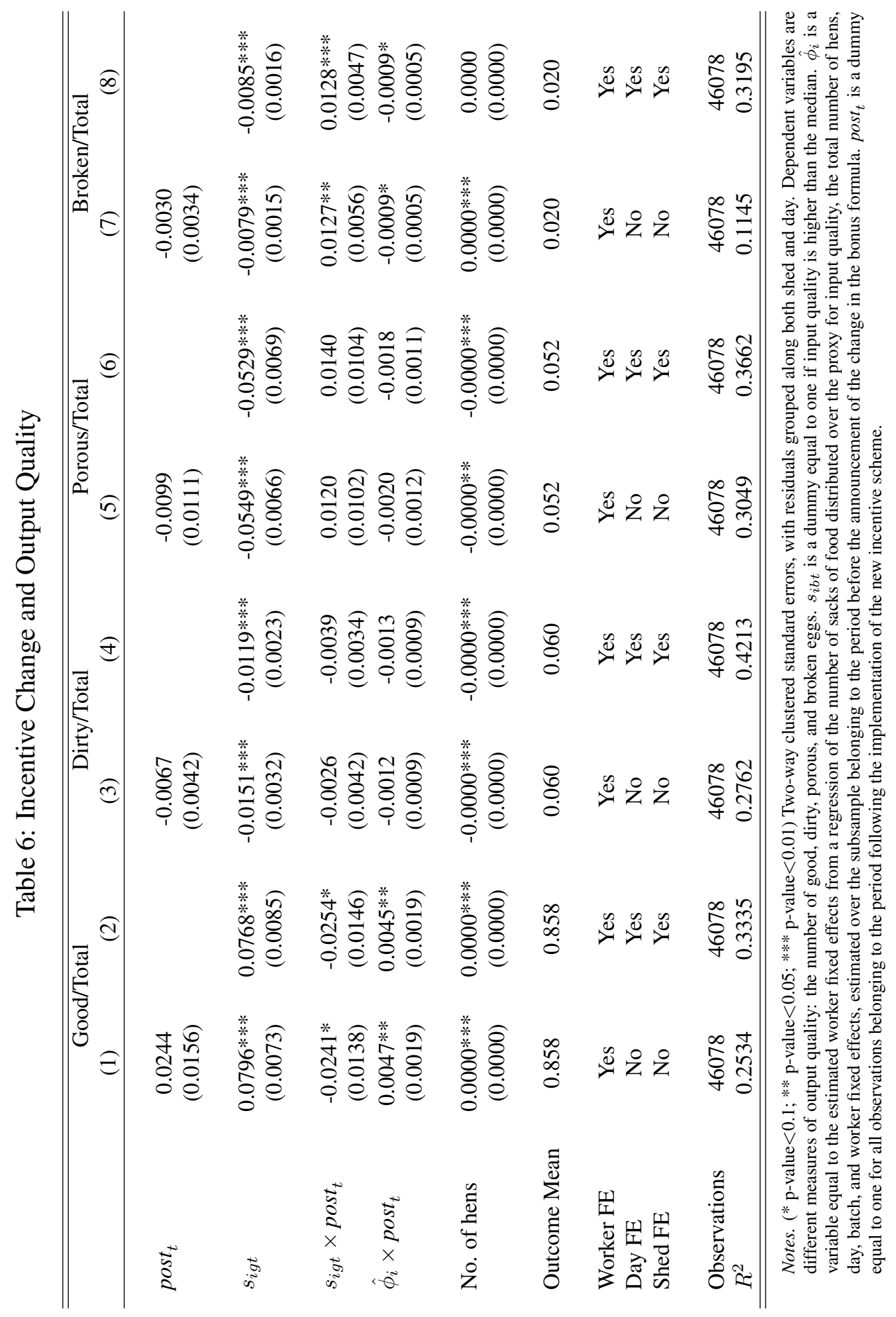


Table 7: Worker Type, Absenteeism and Termination - Odds Ratios

\begin{tabular}{lccc}
\hline \hline & $\begin{array}{c}\text { Absence } \\
(1)\end{array}$ & $\begin{array}{c}\text { Unplanned } \\
(2)\end{array}$ & $\begin{array}{c}\text { Termination } \\
(3)\end{array}$ \\
\hline Before Change & $0.0865^{* * *}$ & $0.0509 * * *$ & $0.0011^{* * *}$ \\
High Productivity & $(0.0048)$ & $(0.0038)$ & $(0.0003)$ \\
Before Change & $0.0584 * * *$ & $0.0331^{* * *}$ & $0.0048^{* * *}$ \\
Low Productivity & $(0.0019)$ & $(0.0013)$ & $(0.0006)$ \\
After Change & $0.0579 * * *$ & $0.0367 * * *$ & $0.0011^{* * *}$ \\
High Productivity & $(0.0024)$ & $(0.0018)$ & $(0.0003)$ \\
After Change & $0.0409 * * *$ & $0.0271 * * *$ & $0.0014 * * *$ \\
Low Productivity & $(0.0015)$ & $(0.0012)$ & $(0.0003)$ \\
& & & \\
Diff-in-Diff & $(0.0021)$ & $(0.0018)$ & $(0.0005)$ \\
& & & 32708 \\
\hline \hline
\end{tabular}

Notes. (* p-value $<0.1 ; * *$ p-value $<0.05 ; * * *$ p-value $<0.01)$ Logit estimates. In column (1), dependent variable is dummy equal to 1 if the worker is absent. In column (2), dependent variable is dummy equal to 1 if the worker is absent without justification. In column (3), dependent variable is dummy equal to 1 if the employment relationship terminates. The table reports the estimated odds ratios for workers whose estimated fixed effects are above and below the median before and after the incentive change, together with the difference in differences. 
Table 8: Worker Type, Input Quality, Absenteeism and Termination - Odds Ratios

\begin{tabular}{|c|c|c|c|}
\hline & $\begin{array}{c}\text { Absence } \\
\text { (1) }\end{array}$ & $\begin{array}{c}\text { Unplanned } \\
\text { (2) }\end{array}$ & $\begin{array}{c}\text { Termination } \\
\text { (3) }\end{array}$ \\
\hline $\begin{array}{l}\text { Before Change } \\
\text { High Productivity } \\
\text { High Input Quality }\end{array}$ & $\begin{array}{c}0.0787 * * * \\
(0.0026)\end{array}$ & $\begin{array}{c}0.0466 * * * \\
(0.0021)\end{array}$ & $\begin{array}{c}0.0008 * * * \\
(0.0002)\end{array}$ \\
\hline $\begin{array}{l}\text { Before Change } \\
\text { Low Productivity } \\
\text { High Input Quality }\end{array}$ & $\begin{array}{c}0.0559 * * * \\
(0.0016)\end{array}$ & $\begin{array}{c}0.0312 * * * \\
(0.0014)\end{array}$ & $\begin{array}{c}0.0039 * * * \\
(0.0008)\end{array}$ \\
\hline $\begin{array}{l}\text { After Change } \\
\text { High Productivity } \\
\text { High Input Quality }\end{array}$ & $\begin{array}{c}0.0575 * * * \\
(0.0014)\end{array}$ & $\begin{array}{c}0.0375 * * * \\
(0.0010)\end{array}$ & $\begin{array}{c}0.0009 * * * \\
(0.0003)\end{array}$ \\
\hline $\begin{array}{l}\text { After Change } \\
\text { Low Productivity } \\
\text { High Input Quality }\end{array}$ & $\begin{array}{c}0.0406 * * * \\
(0.0012)\end{array}$ & $\begin{array}{c}0.0276 * * * \\
(0.0010)\end{array}$ & $\begin{array}{c}0.0011 * * * \\
(0.0003)\end{array}$ \\
\hline $\begin{array}{l}\text { Before Change } \\
\text { High Productivity } \\
\text { Low Input Quality }\end{array}$ & $\begin{array}{c}0.0944 * * * \\
(0.0037)\end{array}$ & $\begin{array}{c}0.0557 * * * \\
(0.0035)\end{array}$ & $\begin{array}{c}0.0015 * * * \\
(0.0005)\end{array}$ \\
\hline $\begin{array}{l}\text { Before Change } \\
\text { Low Productivity } \\
\text { Low Input Quality }\end{array}$ & $\begin{array}{c}0.0606 * * * \\
(0.0016)\end{array}$ & $\begin{array}{c}0.0349 * * * \\
(0.0015)\end{array}$ & $\begin{array}{c}0.0053 * * * \\
(0.0008)\end{array}$ \\
\hline $\begin{array}{l}\text { After Change } \\
\text { High Productivity } \\
\text { Low Input Quality }\end{array}$ & $\begin{array}{c}0.0584 * * * \\
(0.0016)\end{array}$ & $\begin{array}{c}0.0359 * * * \\
(0.0014)\end{array}$ & $\begin{array}{c}0.0013 * * * \\
(0.0004)\end{array}$ \\
\hline $\begin{array}{l}\text { After Change } \\
\text { Low Productivity } \\
\text { Low Input Quality }\end{array}$ & $\begin{array}{c}0.0412 * * * \\
(0.0013)\end{array}$ & $\begin{array}{c}0.0267 * * * \\
(0.0012)\end{array}$ & $\begin{array}{c}0.0016 * * * \\
(0.0004)\end{array}$ \\
\hline Triple-Diff & $\begin{array}{c}0.0108 * * * \\
(0.0010)\end{array}$ & $\begin{array}{c}0.0062 * * * \\
(0.0011)\end{array}$ & $\begin{array}{c}-0.0004 \\
(0.0007)\end{array}$ \\
\hline Observations & 36542 & 37595 & 32708 \\
\hline
\end{tabular}

Notes. ( $* \mathrm{p}$-value $<0.1 ; * * \mathrm{p}$-value $<0.05$; *** $\mathrm{p}$-value $<0.01)$ Logit estimates. In column $(1)$, dependent variable is dummy equal to 1 if the worker is absent. In column (2), dependent variable is dummy equal to 1 if the worker is absent without previous plannification. In column (3), dependent variable is dummy equal to 1 if the employment relationship terminates. The table reports the estimated odds ratios for workers whose estimated fixed effects are above and below the median before and after the incentive change, and separately for assigned input quality above and below the median, together with the corresponding triple differences. 
Figure 1: Food Choice Over Time

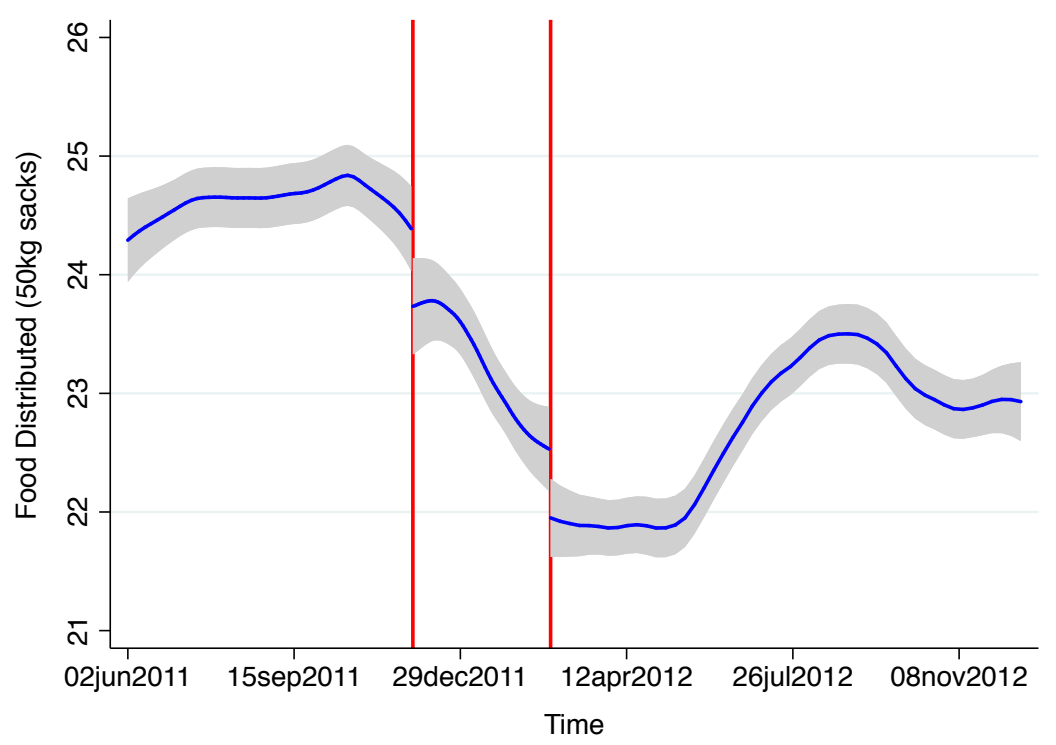

Notes. The figure plots the smoothed average of the total number of $50 \mathrm{kgs}$ sacks of food distributed across all production units in a given day, together with its $95 \%$ confidence interval. Residuals are obtained from a regression of the number sacks distributed over the proxy for input quality and worker fixed effects. The two vertical lines correspond to the dates of announcement and implementation of the new incentive scheme. The amount of food distributed is stable before the announcement, falls discontinuously on announcement and implementation dates, and stabilizes again in the later period at a level that is lower than the initial one. 
Figure 2: Food Intake and Output

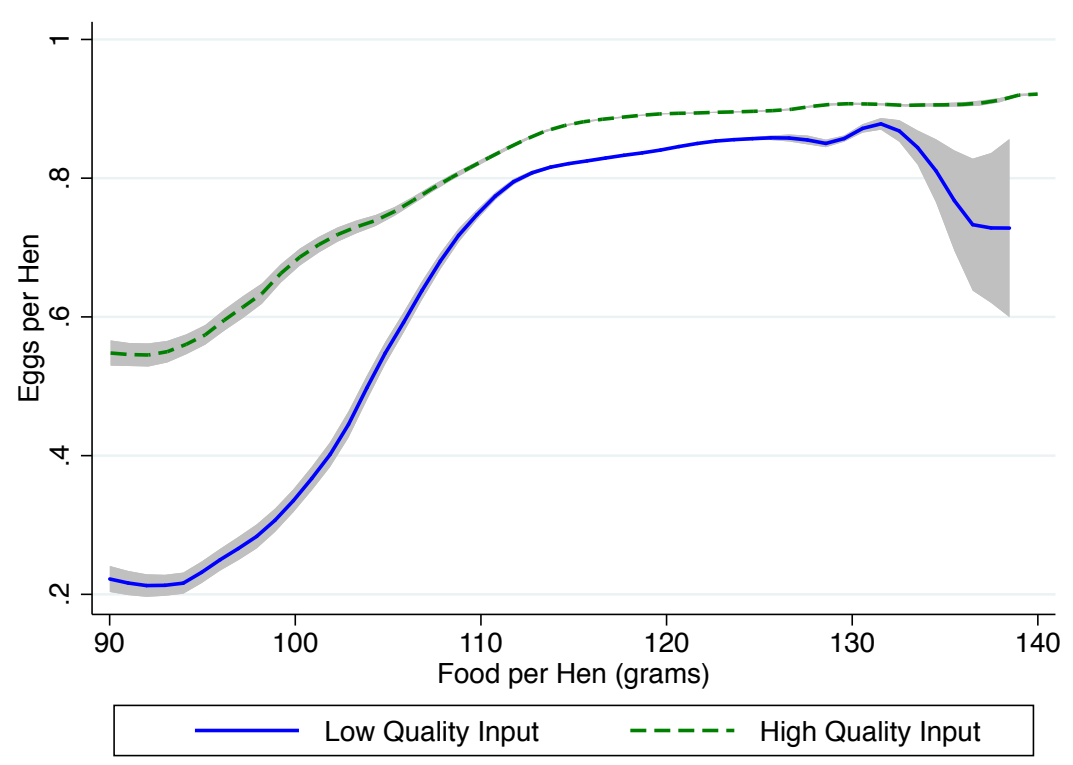

Notes. The figure plots the smoothed average of the number of eggs per hen collected by the worker over the grams of food per hen distributed in the day, together with its $95 \%$ confidence interval. It does so separately for production units endowed with batch of above and below median quality, where the latter is measured using the expected productivity measure available from the supplier company upon purchasing the batch. 
Figure 3: Incentive Change and Input Quality

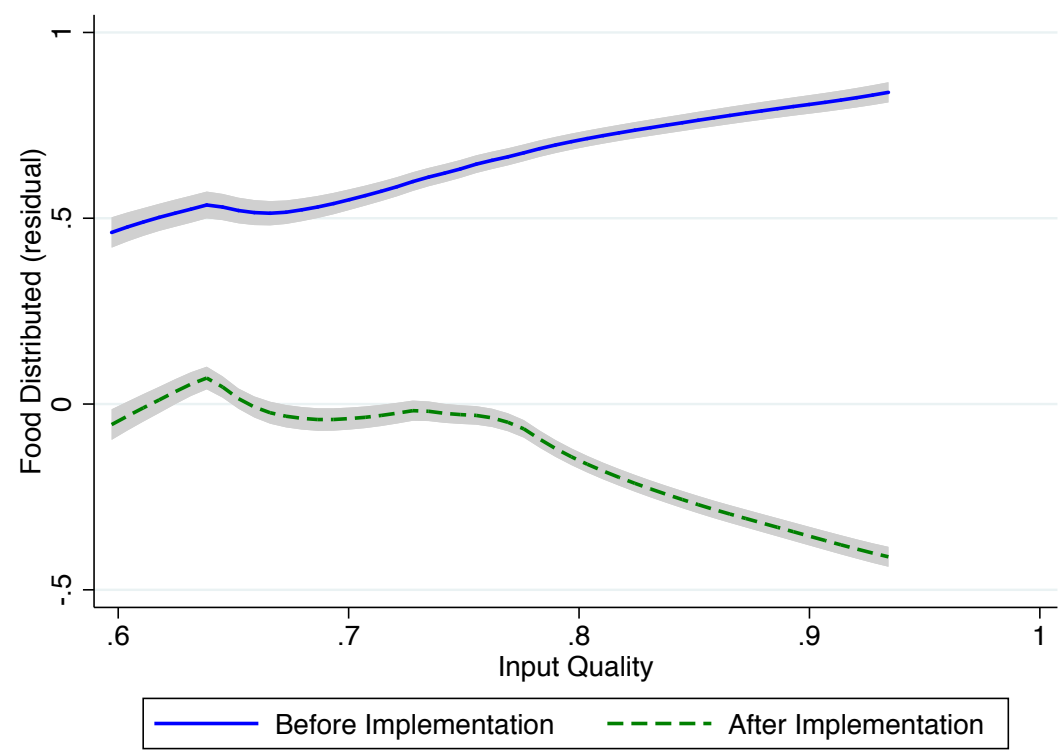

Notes. The figure plots the smoothed average of the number of sacks of food distributed across all production units endowed with inputs of different quality, together with its $95 \%$ confidence interval. It does so separately for observations belonging to the period before and after the incentive change. Residuals are obtained from a regression of the number sacks distributed over worker fixed effects and the total number of hens. 
Figure 4: Food Choice and Input Quality Over Time

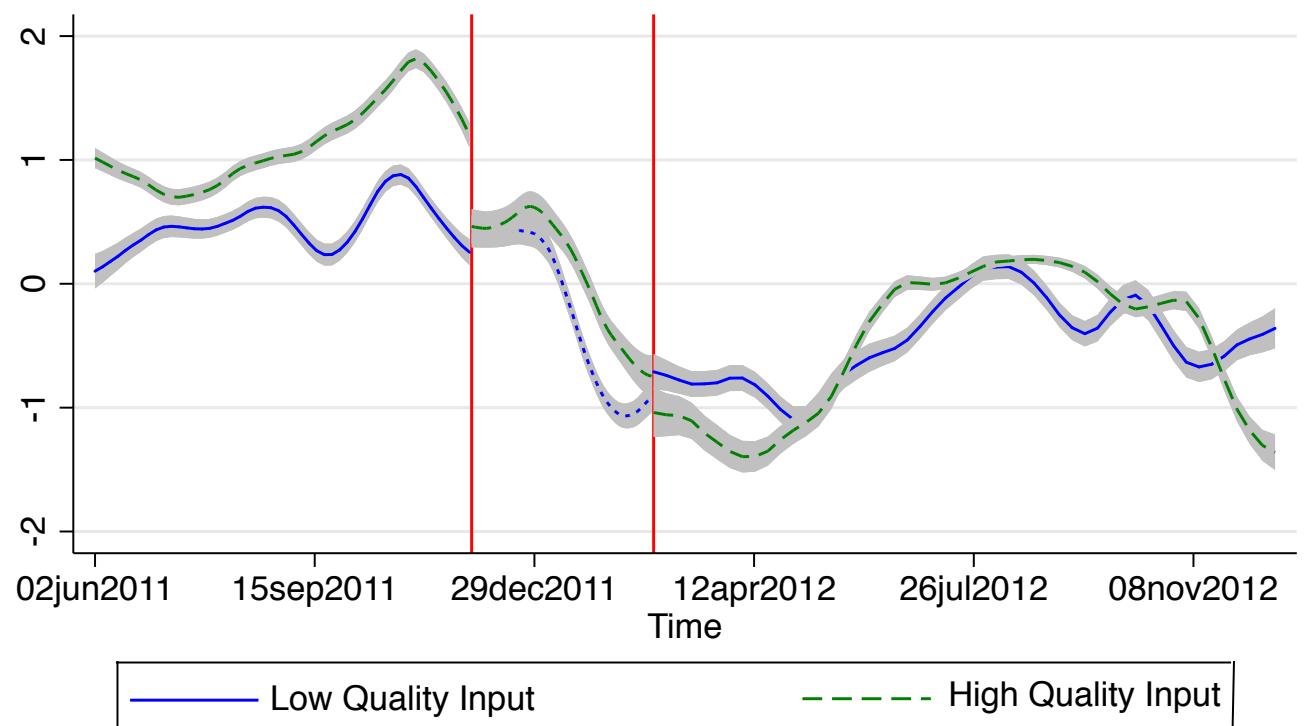

Notes. The figure plots the smoothed average of residual food distributed over time, and separately for production units endowed with batches with input quality higher and lower than the median. Residuals are obtained from a regression of the total number of sacks of food distributed over the total number of hens and worker fixed effects. The two vertical red lines correspond to the dates of announcement and implementation of the new salary scheme. 
Figure 5: Distribution of Worker Type

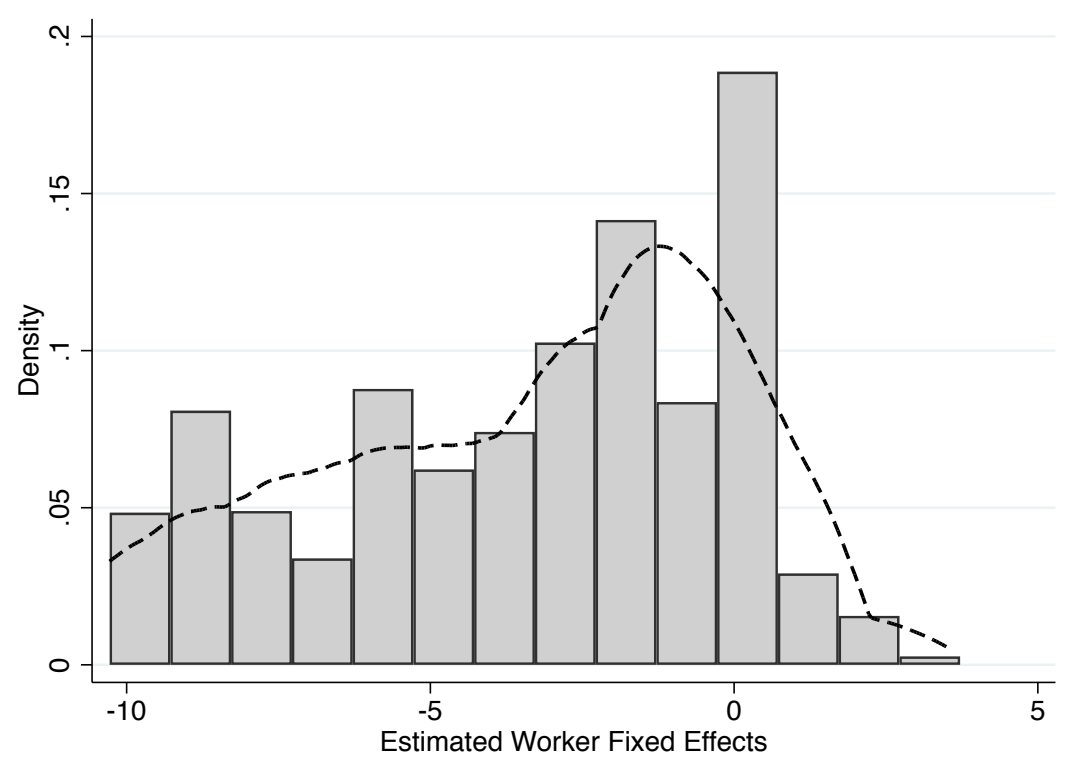

Notes. The figure plots the estimated worker fixed effects from a regression of the number of sacks of food distributed over the proxy for input quality, the total number of hens, day, batch, and worker fixed effects, estimated over the subsample belonging to the period before the announcement of the change in the bonus formula. 
Figure 6: Food Choice and Worker Type Over Time

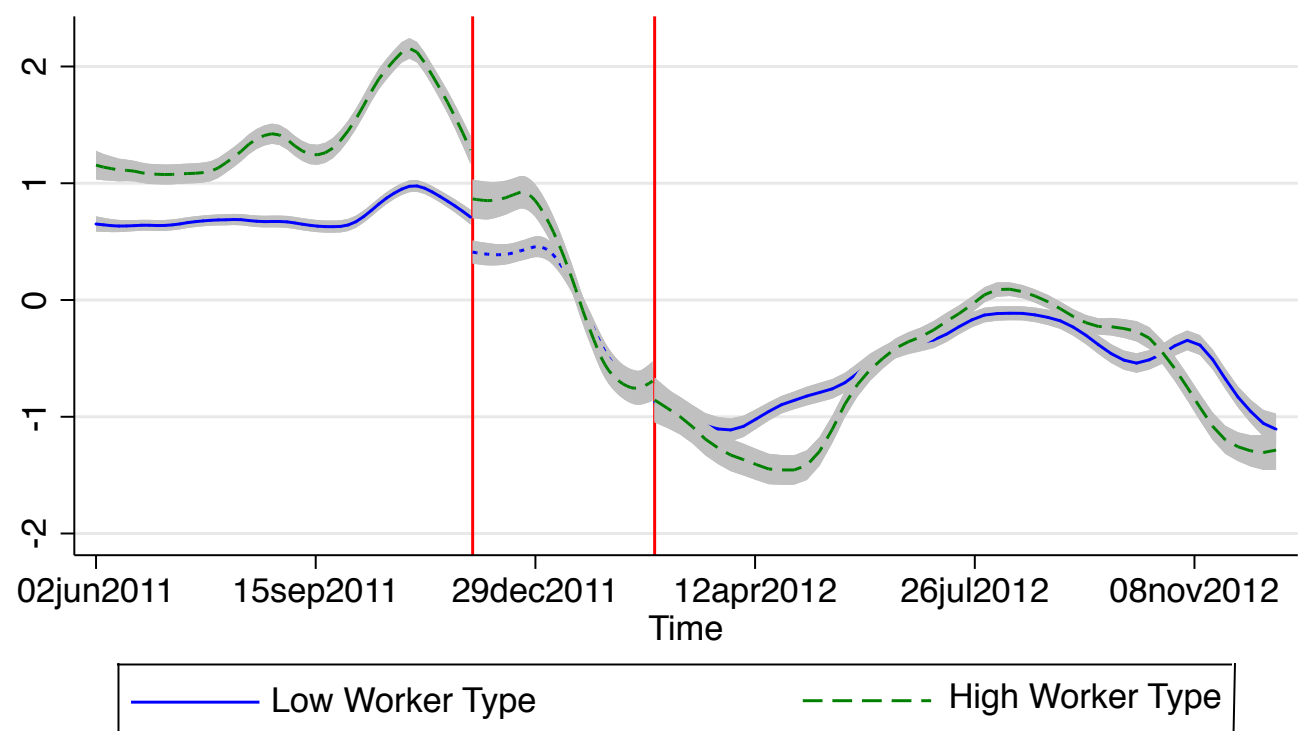

Notes. The figure plots the smoothed average of residual food distributed over time, and separately for production units operated by workers with $\phi_{i}$ higher and lower than the median. Residuals are obtained from a regression of the total number of sacks of food distributed over the total number of hens and the measure of input quality. The two vertical red lines correspond to the dates of announcement and implementation of the new salary scheme. 


\section{A Appendix}

\section{A.1 Additional Tables and Figures}

Table A.1: Worker's Typical Working Day

\begin{tabular}{ll}
\hline \hline 6.20am & Breakfast at the cafeteria, a truck takes them to the assigned production unit \\
$7.00 \mathrm{am}$ & Hens' feeding, food distribution and even up \\
$9.00 \mathrm{am}$ & Egg collection \\
$11.30 \mathrm{am}$ & Egg classification (good, dirty, porous and broken) and cleaning \\
$12.30 \mathrm{am}$ & Truck arrives to collect egg baskets \\
$1.00 \mathrm{pm}$ & Lunch at the cafeteria \\
$1.30 \mathrm{pm}$ & Eggs moved to boxes \\
$2.30 \mathrm{pm}$ & Truck takes them back to production unit \\
$3.00 \mathrm{pm}$ & Cleaning of cages and facilities \\
$3.30 \mathrm{pm}$ & Hens' feeding, food distribution and even up \\
$5.00 \mathrm{pm}$ & End of working day \\
\hline \hline
\end{tabular}


Table A.2: Summary Statistics

\begin{tabular}{|c|c|c|c|c|c|}
\hline Variable & Mean & Std. Dev. & Min. & Max. & $\mathrm{N}$ \\
\hline & \multicolumn{5}{|c|}{ Panel A. Production Units } \\
\hline Food Distributed (50kg sacks) & 23.402 & 8.705 & 0.5 & 39 & 46049 \\
\hline Input Quality & 0.811 & 0.147 & 0.02 & 0.934 & 44985 \\
\hline No. of Hens & 10105.576 & 3672.284 & 353 & 15985 & 46049 \\
\hline Food per Hen (gr) & 115.771 & 9.495 & 66.774 & 163.235 & 46049 \\
\hline Total Eggs Collected & 8140.025 & 3574.481 & 0 & 15131 & 46049 \\
\hline Total Eggs per Hen & 0.803 & 0.19 & 0 & 1 & 46049 \\
\hline Food Distributed by Coworkers (avg) & 24.255 & 7.302 & 1 & 35.5 & 42281 \\
\hline Coworkers' Total Eggs per Hen (avg) & 0.807 & 0.154 & 0 & 1 & 42281 \\
\hline Good/Total & 0.858 & 0.089 & 0 & 1.766 & 40082 \\
\hline Dirty/Total & 0.060 & 0.043 & 0 & 0.769 & 40082 \\
\hline Porous/Total & 0.052 & 0.061 & 0 & 1 & 40082 \\
\hline Broken/Total & 0.020 & 0.030 & 0 & 0.5 & 40082 \\
\hline Absences & 0.049 & 0.216 & 0 & 1 & 46346 \\
\hline \multirow[t]{2}{*}{ Unplanned Abs. } & 0.029 & 0.167 & 0 & 1 & 46346 \\
\hline & \multicolumn{5}{|c|}{ Panel B. Workers } \\
\hline Absences & 0.087 & 0.150 & 0 & 1 & 126 \\
\hline Unplanned Abs. & 0.035 & 0.046 & 0 & 0.317 & 127 \\
\hline
\end{tabular}

Notes. The table reports the summary statistics of the variable used in the empirical analysis. 
Table A.3: Incentive Change and Worker Types - Bootstrapped Standard Errors

\begin{tabular}{|c|c|c|c|c|c|}
\hline & \multicolumn{5}{|c|}{ Food Distributed } \\
\hline post $_{t}$ & $\begin{array}{c}-1.5157 * * * \\
(0.2279)\end{array}$ & $\begin{array}{c}-1.4610 * * * \\
(0.2508)\end{array}$ & & & \\
\hline$\hat{\phi}_{i}$ & $\begin{array}{c}0.1287 * * * \\
(0.0314)\end{array}$ & & & & \\
\hline$\hat{\phi}_{i} \times$ post $_{t}$ & $\begin{array}{c}-0.1272 * * * \\
(0.0316)\end{array}$ & $\begin{array}{c}-0.1347 * * * \\
(0.0335)\end{array}$ & $\begin{array}{c}-0.1488 * * * \\
(0.0266)\end{array}$ & $\begin{array}{c}-0.1602 * * * \\
(0.0305)\end{array}$ & $\begin{array}{c}-0.1976 * * * \\
(0.0365)\end{array}$ \\
\hline$\hat{\phi}_{i} \times a n n_{t}$ & & & & & $\begin{array}{c}-0.1112 * * * \\
(0.0250)\end{array}$ \\
\hline$s_{i g t}$ & $\begin{array}{c}0.3811 * * * \\
(0.0195)\end{array}$ & $\begin{array}{c}0.3628 * * * \\
(0.0197)\end{array}$ & $\begin{array}{c}0.2700 * * * \\
(0.01988)\end{array}$ & $\begin{array}{c}0.3753^{* * * *} \\
(0.0205)\end{array}$ & $\begin{array}{c}0.3756 * * * \\
(0.0209)\end{array}$ \\
\hline No. of Hens & $\begin{array}{c}0.0023^{* * * *} \\
(0.0000)\end{array}$ & $\begin{array}{c}0.0022 * * * \\
(0.0000)\end{array}$ & $\begin{array}{c}0.0022 * * * \\
(0.0000)\end{array}$ & $\begin{array}{c}0.0020 * * * \\
(0.0000)\end{array}$ & $\begin{array}{c}0.0020 * * * \\
(0.0000)\end{array}$ \\
\hline Worker FE & No & Yes & Yes & Yes & Yes \\
\hline Day FE & No & No & Yes & Yes & Yes \\
\hline Shed FE & No & No & No & Yes & Yes \\
\hline Observations & 46346 & 46345 & 46345 & 46345 & 46345 \\
\hline
\end{tabular}

Notes. $(*$ p-value $<0.1 ; * *$ p-value $<0.05 ; * * *$ p-value $<0.01)$ Empirical standard errors obtained by implementing a bootstrapping procedure and estimating the coefficients over 500 random samples with replacement. Dependent variable is the amount of food distributed by the worker on a given day as measured by the number of $50 \mathrm{~kg}$ sacks distributed. $s_{i b t}$ is a dummy equal to one if input quality is higher than the median. $\hat{\phi}_{i}$ is a variable equal to the estimated worker fixed effects from a regression of the number of sacks of food distributed over the proxy for input quality, the total number of hens, day, batch, and worker fixed effects, estimated over the subsample belonging to the period before the announcement of the change in the bonus formula. post $t_{t}$ is a dummy equal to one for all observations belonging to the period following the implementation of the new incentive scheme. $a n_{t}$ is a dummy equal to one for all observations belonging to the period between the announcement and the implementation of the new scheme. 
Table A.4: Incentive Change, Input Quality and Worker Types - Continuous $s_{\text {igt }}$

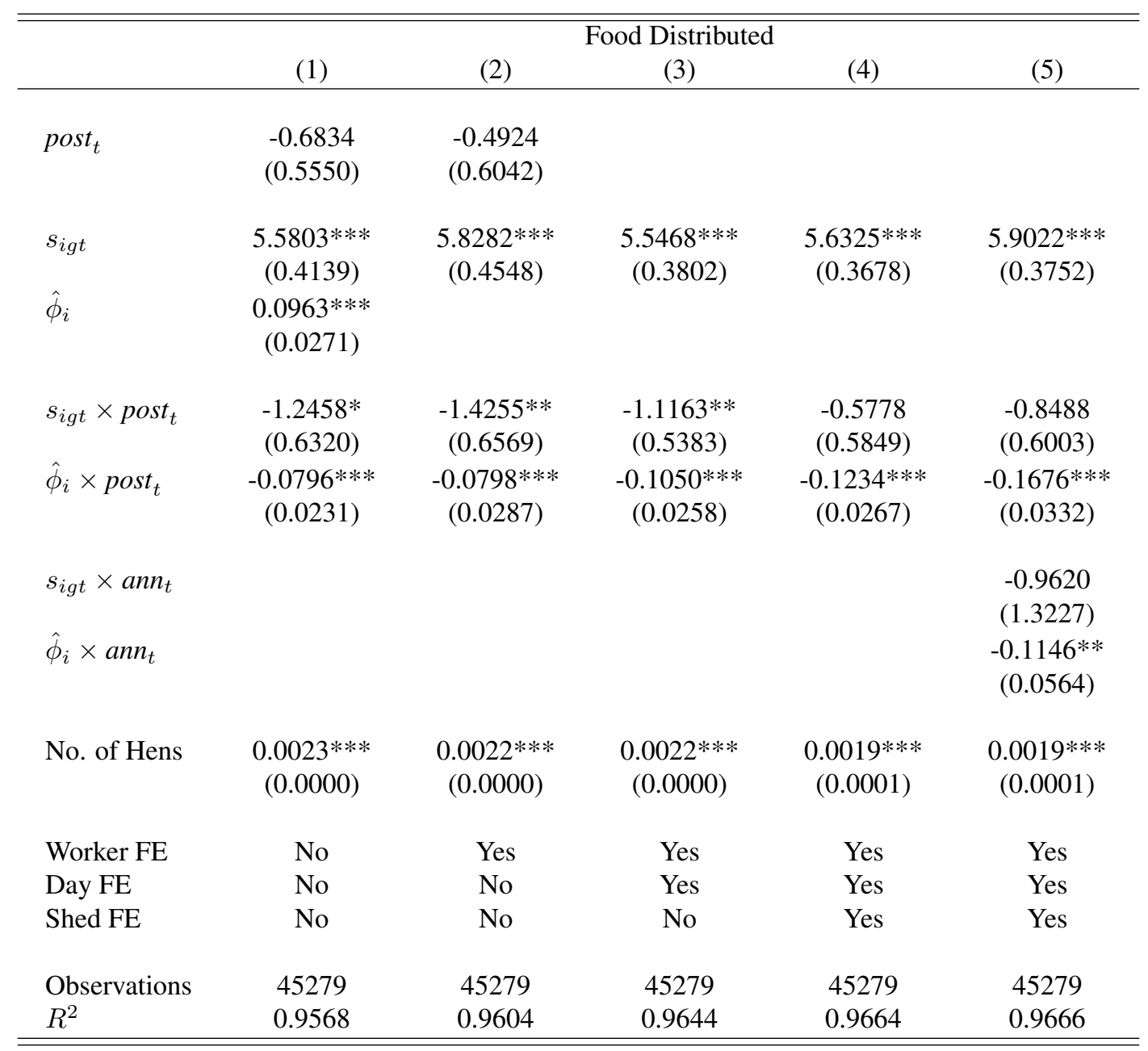

Notes. (* p-value $<0.1 ; * *$ p-value $<0.05 ; * * *$ p-value $<0.01)$ Two-way clustered standard errors, with residuals grouped along both shed and day. Dependent variable is the amount of food distributed by the worker on a given day as measured by the number of $50 \mathrm{~kg}$ sacks distributed. $s_{i b t}$ is the continuous input quality measure. $\hat{\phi}_{i}$ is a variable equal to the estimated worker fixed effects from a regression of the number of sacks of food distributed over the proxy for input quality, the total number of hens, day, batch, and worker fixed effects, estimated over the subsample belonging to the period before the announcement of the change in the bonus formula. post $t_{t}$ is a dummy equal to one for all observations belonging to the period following the implementation of the new incentive scheme. $a n_{t}$ is a dummy equal to one for all observations belonging to the period between the announcement and the implementation of the new scheme. 
Table A.5: Incentive Change and Output: Announcement and Implementation

\begin{tabular}{|c|c|c|c|c|}
\hline & \multicolumn{4}{|c|}{ Total No. of Eggs Boxes Collected } \\
\hline & (1) & (2) & (3) & (4) \\
\hline \multirow[t]{2}{*}{ post $_{t}$} & $-1.3990 *$ & -1.3002 & & \\
\hline & $(0.7841)$ & $(0.8709)$ & & \\
\hline \multirow[t]{2}{*}{$a n n_{t}$} & -0.1472 & -0.4936 & & \\
\hline & $(1.3321)$ & $(1.3369)$ & & \\
\hline \multirow[t]{2}{*}{$s_{i g t}$} & $3.2589 * * *$ & $3.7349 * * *$ & $3.7399 * * *$ & $3.9290 * * *$ \\
\hline & $(0.5315)$ & $(0.6417)$ & $(0.6246)$ & $(0.6544)$ \\
\hline \multirow[t]{2}{*}{$\hat{\phi}_{i}$} & 0.0343 & & & \\
\hline & $(0.0678)$ & & & \\
\hline \multirow[t]{2}{*}{$s_{i g t} \times$ post $_{t}$} & -0.5015 & -0.8070 & -0.8737 & -0.7071 \\
\hline & $(0.7205)$ & $(0.8124)$ & $(0.6963)$ & $(0.7557)$ \\
\hline \multirow[t]{2}{*}{$\hat{\phi}_{i} \times$ post $_{t}$} & -0.0479 & -0.0436 & -0.0488 & -0.0634 \\
\hline & $(0.0661)$ & $(0.0756)$ & $(0.0769)$ & $(0.0805)$ \\
\hline \multirow[t]{2}{*}{$s_{i g t} \times a n n_{t}$} & $-1.8327 *$ & $-1.8170 *$ & $-1.9989 *$ & -1.8645 \\
\hline & $(0.9267)$ & $(1.0418)$ & $(1.0511)$ & (1.1134) \\
\hline \multirow[t]{2}{*}{$\hat{\phi}_{i} \times a n n_{t}$} & -0.0548 & -0.1077 & -0.0923 & -0.0809 \\
\hline & $(0.1388)$ & $(0.1430)$ & $(0.1396)$ & $(0.1458)$ \\
\hline \multirow[t]{2}{*}{ No. of Hens } & $0.0022 * * *$ & $0.0020 * * *$ & $0.0020 * * *$ & $0.0016 * * *$ \\
\hline & $(0.0000)$ & $(0.0000)$ & $(0.0000)$ & $(0.0001)$ \\
\hline Worker FE & No & Yes & Yes & Yes \\
\hline Day FE & No & No & Yes & Yes \\
\hline Shed FE & No & No & No & Yes \\
\hline Observations & 46346 & 46345 & 46345 & 46345 \\
\hline$R^{2}$ & 0.7024 & 0.7256 & 0.7334 & 0.7388 \\
\hline
\end{tabular}

Notes. (* p-value $<0.1 ; * *$ p-value $<0.05 ; * * * \mathrm{p}$-value $<0.01)$ Two-way clustered standard errors, with residuals grouped along both shed and day. Dependent variable is total output as measured by the total amount of eggs boxes collected by the worker on a given day. Eggs boxes contain 360 eggs. $s_{i b t}$ is a dummy equal to one if input quality is higher than the median. $\hat{\phi}_{i}$ is a variable equal to the estimated worker fixed effects from a regression of the number of sacks of food distributed over the proxy for input quality, the total number of hens, day, batch, and worker fixed effects, estimated over the subsample belonging to the period before the announcement of the change in the bonus formula. post $_{t}$ is a dummy equal to one for all observations belonging to the period following the implementation of the new incentive scheme. 
Table A.6: Incentive Change and Bonus Paid - Announcement and Implementation

\begin{tabular}{|c|c|c|c|c|}
\hline & \multicolumn{4}{|c|}{ Bonus Paid (derived) } \\
\hline & (1) & (2) & (3) & (4) \\
\hline post $_{t}$ & $\begin{array}{c}-2.6741^{* * *} * \\
(0.5290)\end{array}$ & $\begin{array}{c}-2.6029 * * * \\
(0.6365)\end{array}$ & & \\
\hline$a n n_{t}$ & $\begin{array}{l}-0.6855 \\
(0.8441)\end{array}$ & $\begin{array}{l}-0.8720 \\
(0.8487)\end{array}$ & & \\
\hline$s_{i g t}$ & $\begin{array}{c}2.0180 * * * \\
(0.3259)\end{array}$ & $\begin{array}{c}2.3201 * * * \\
(0.4268)\end{array}$ & $\begin{array}{c}2.3151^{* * * *} \\
(0.4160)\end{array}$ & $\begin{array}{c}2.4370 * * * \\
(0.4332)\end{array}$ \\
\hline$\hat{\phi}_{i}$ & $\begin{array}{l}0.0888 * \\
(0.0484)\end{array}$ & & & \\
\hline$s_{i g t} \times$ post $_{t}$ & $\begin{array}{c}-1.0338 * \\
(0.5906)\end{array}$ & $\begin{array}{c}-1.2204 * \\
(0.6732)\end{array}$ & $\begin{array}{c}-1.3955^{*} \\
(0.6910)\end{array}$ & $\begin{array}{c}-1.2901 * \\
(0.7382)\end{array}$ \\
\hline$\hat{\phi}_{i} \times$ post $_{t}$ & $\begin{array}{c}-0.0702 \\
(0.0923)\end{array}$ & $\begin{array}{c}-0.1064 \\
(0.0958)\end{array}$ & $\begin{array}{l}-0.0910 \\
(0.0932)\end{array}$ & $\begin{array}{c}-0.0770 \\
(0.0976)\end{array}$ \\
\hline$s_{i g t} \times a n n_{t}$ & $\begin{array}{c}0.7260 \\
(0.5588)\end{array}$ & $\begin{array}{c}0.5953 \\
(0.6423)\end{array}$ & $\begin{array}{c}0.5389 \\
(0.5443)\end{array}$ & $\begin{array}{c}0.7356 \\
(0.5904)\end{array}$ \\
\hline$\hat{\phi}_{i} \times a n n_{t}$ & $\begin{array}{c}-0.1088 * * \\
(0.0497)\end{array}$ & $\begin{array}{c}-0.1001 * \\
(0.0588)\end{array}$ & $\begin{array}{c}-0.1040 * \\
(0.0595)\end{array}$ & $\begin{array}{c}-0.1183 * \\
(0.0623)\end{array}$ \\
\hline No. of Hens & $\begin{array}{c}0.0022 * * * \\
(0.0000)\end{array}$ & $\begin{array}{c}0.0020 * * * \\
(0.0000)\end{array}$ & $\begin{array}{c}0.0020^{* * *} * \\
(0.0000)\end{array}$ & $\begin{array}{c}0.0017 * * * \\
(0.0001)\end{array}$ \\
\hline Worker FE & No & Yes & Yes & Yes \\
\hline Day FE & No & No & Yes & Yes \\
\hline Shed FE & No & No & No & Yes \\
\hline Observations & 46346 & 46345 & 46345 & 46345 \\
\hline$R^{2}$ & 0.7566 & 0.7754 & 0.7828 & 0.7868 \\
\hline
\end{tabular}

Notes. (* p-value $<0.1 ; * * \mathrm{p}$-value $<0.05 ; * * * \mathrm{p}$-value $<0.01)$ Two-way clustered standard errors, with residuals grouped along both shed and day. Sample is restricted to those observations belonging to the period before announcement and after implementation of the new incentive scheme. Dependent variable is a proxy for the bonus paid to workers derived using the number of eggs collected, the total amount of sacks of food distributed, and the bonus formula before and after the incentive change, as explained in Section 5.3. $s_{i b t}$ is a dummy equal to one if input quality is higher than the median. $\hat{\phi}_{i}$ is a variable equal to the estimated worker fixed effects from a regression of the number of sacks of food distributed over the proxy for input quality, the total number of hens, day, batch, and worker fixed effects, estimated over the subsample belonging to the period before the announcement of the change in the bonus formula. post $_{t}$ is a dummy equal to one for all observations belonging to the period following the implementation of the new incentive scheme. 


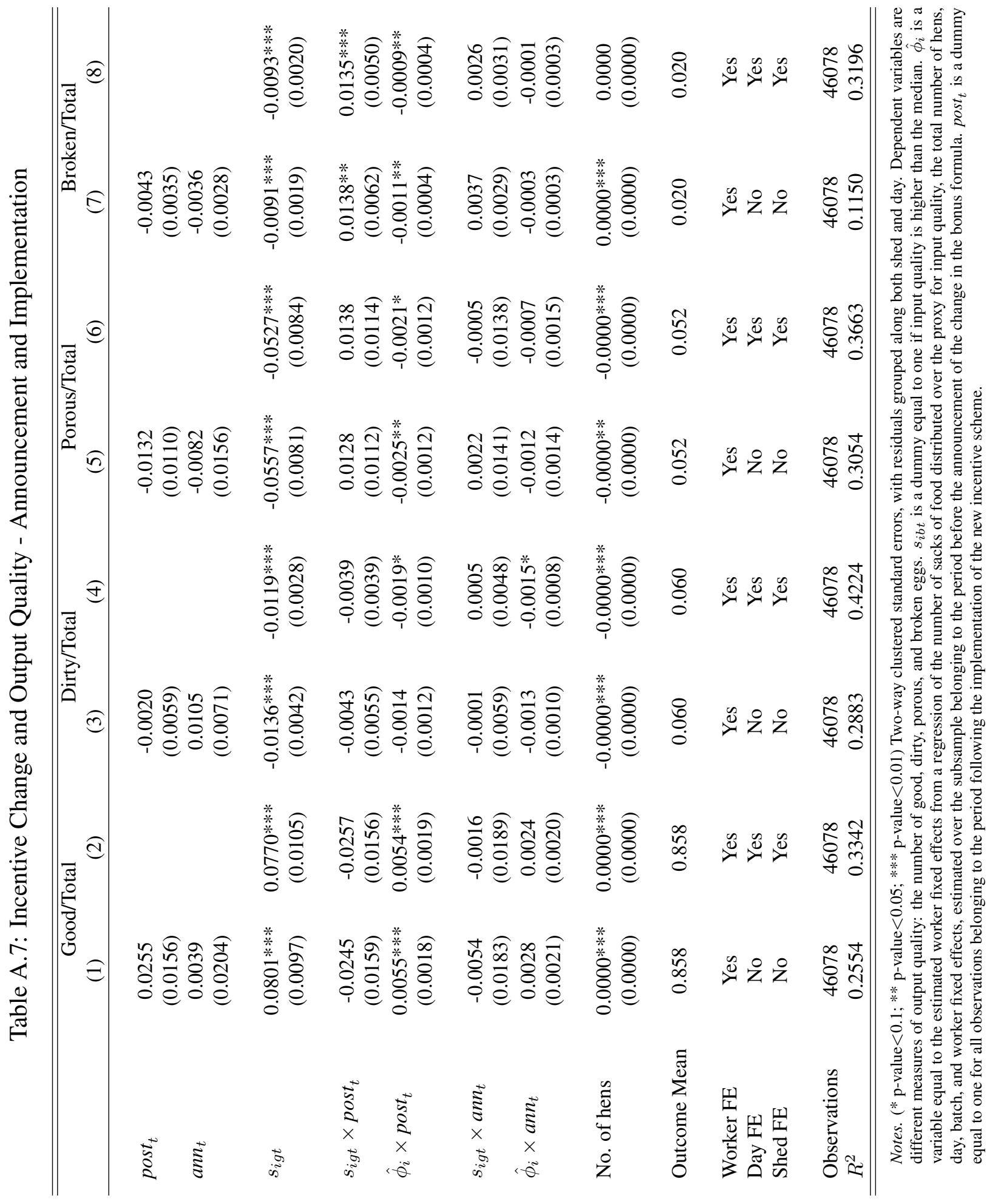


Figure A.1: One Sector

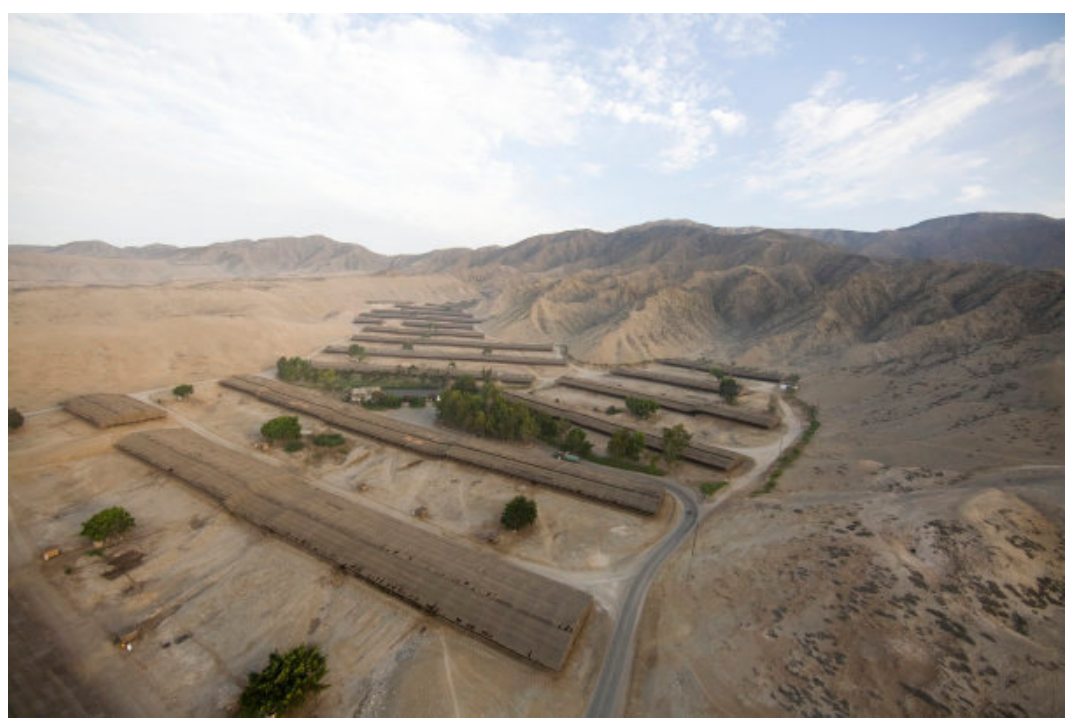

Notes. The picture shows a given production sector in the plant under investigation. Each one of the long-shaped building is a shed.

Figure A.2: Production Units

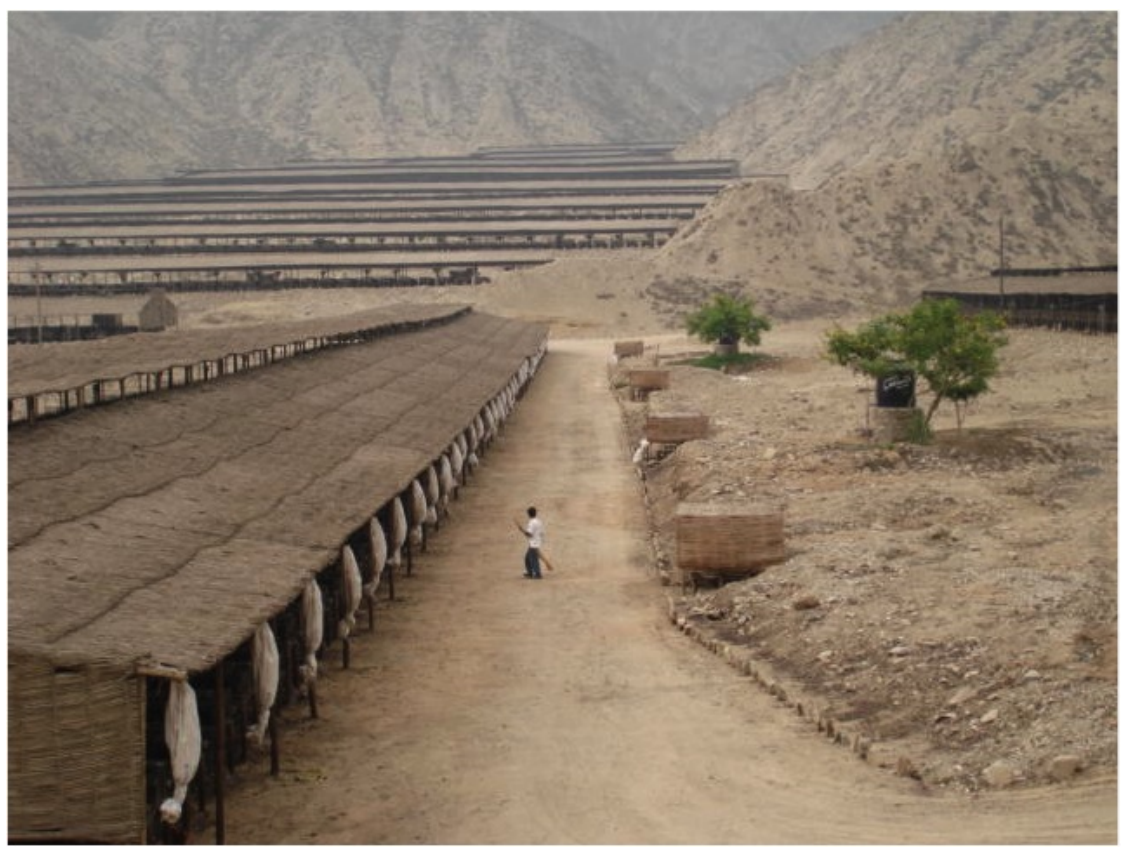

Notes. The picture of a particular shed hosting four production units. Each production unit is defined by one worker and the batch of laying hens assigned to him. We can distinguish in the picture the four production unit's warehouses located across the street from the shed. 


\section{A.2 Optimal Linear Contract}

In this section, we derive the value of $\alpha$ that is optimal for the principal after assuming a shape of the production function that matches our setting. In our application, the concavity of output with respect to effort is lower when input quality increases, meaning $\partial^{3} f\left(s_{i}, a_{i}\right) / \partial a_{i}^{2} s_{i}>0$. We incorporate this property parsimoniously in a production function of the form

$$
y_{i}=\frac{1}{s_{i}}\left(a_{i}-a_{i}^{2}\right)
$$

Solving for $a_{i}$ in the first order condition of the worker's maximization problem in equation 4 of Section 2 yields

$$
a_{i}^{*}=\frac{1}{2}-\frac{s_{i}}{2}\left(1-\frac{1-\theta_{i}}{\alpha}\right)
$$

In our setting, worker's effort $a_{i}$ maps into number of sacks of food distributed. Since food is costly, this enters the principal's payoff directly together with output. We assume the principal to be risk neutral and have a linear utility that is given by

$$
v_{i}=y_{i}-w_{i}-\gamma a_{i}
$$

where $\gamma$ is the cost of food per unit of worker's effort, and $w_{i}=f+\alpha y_{i}+(1-\alpha) a_{i}$. The problem of the principal is to find the values of $f$ and $\alpha$ that maximize her payoff. In doing this, she takes into account the optimal choice of the worker in equation A.2 above, and her participation constraint. We assume without loss of generality that the value of the outside option for the worker is equal to zero. We thus have

$$
f^{*}=\frac{\eta}{2} \alpha^{2} \sigma^{2}+\theta_{i} a_{i}^{*}-\alpha y_{i}\left(s_{i}, a_{i}^{*}\right)-(1-\alpha) a_{i}^{*}
$$

where

$$
y_{i}\left(s_{i}, a_{i}^{*}\right)=\frac{1}{s_{i}}\left[\frac{1}{4}-\frac{s_{i}^{2}}{4}\left(1-\frac{1-\theta_{i}}{\alpha}\right)^{2}\right]
$$


The principal chooses $\alpha$ that maximizes

$$
v_{i}=y_{i}\left(s_{i}, a_{i}^{*}\right)-\frac{\eta}{2} \alpha^{2} \sigma^{2}-\theta_{i} a_{i}^{*}-\gamma a_{i}
$$

It can be shown that if $\gamma=0$ and $\sigma^{2}=0$ the optimal value of $\alpha$ is equal to one. This is because the principal bears no cost associated with worker's effort, and the worker is risk neutral: the contract with $\alpha=1$ implements the first-best allocation of effort. With $\gamma>0$ and $\sigma^{2}=0$, the optimal value of $\alpha$ is greater than one: the principal attaches a negative weight to worker's effort as that is associated with additional costs. However, if $\sigma^{2}$ is sufficiently high, the optimal $\alpha$ is positive but lower than one. This is because incentives on output make the worker bear risk, while, despite the negative sign in the principal's payoff, incentives on effort work as an insurance mechanism.

\section{A.3 Model Extension: Multi-tasking}

This section extends the previous model and informational structure to show that the same predictions hold in a multi-tasking setting. Consider two effort variables, $a_{1}$ and $a_{2}$, each of them related to a particular action. In our setting, these different actions can be feeding the hens and collecting eggs. Notice that feeding effort is closely captured by the amount of food distributed among hens, but the effort devoted to egg collection has no clean performance measure attached: the total amount of eggs a worker collects depends on effort and input quality. Second, unlike some formulations of the multi-tasking setting, these efforts do not compete for a given amount of time of effort, since there is a predetermined schedule for the workers as shown in Table A.1. The latter is important because what matters is the intensity of the effort provided and not the amount of time spent on a given task, which implies that we can rule out corner solutions. Taking into account the previous considerations we assume a production function of the form

$$
y_{i}=f\left(a_{1 i}, a_{2 i}, s_{i}\right)+\epsilon_{i}
$$

As before, the cost of effort is linear, $C\left(a_{i}\right)=\theta_{i} a_{i}$ where $\theta_{i}>0$ and $a_{i}=a_{1 i}+a_{2 i}$. The wage is 
equal to $w_{i}=f+\alpha y_{i}+(1-\alpha) a_{1 i}$. The manager observes perfectly feeding effort $a_{1 i}$ and uses this information in the contract to reduce the risk borne by workers. Given the CARA utility function of the workers, we can solve for the first order conditions of the worker's problem:

$$
\begin{gathered}
\frac{\partial f}{\partial a_{1 i}}=1-\left(\frac{1-\theta_{i}}{\alpha}\right) \\
\frac{\partial f}{\partial a_{2 i}}=\frac{\theta_{i}}{\alpha}
\end{gathered}
$$

Notice that the equation determining $a_{1 i}$ is the same first order condition we obtained before in Section 2. However, the worker can adjust now both effort levels as a response to the change in the contract parameters. We obtain the same predictions of Section 2 in the multi-tasking context when the following conditions are met

1. The production function is concave is both effort types, i.e. $\frac{\partial f}{\partial a_{i}}>0$ and $\frac{\partial^{2} f}{\partial a_{i}^{2}}<0$ for $i=1,2$;

2. Direct effects are stronger than indirect effects over the slope of the production function with respect to both effort types, i.e. $\left|\frac{\partial^{2} f}{\partial a_{i}^{2}}\right|>\left|\frac{\partial^{2} f}{\partial a_{1} \partial a_{2}}\right|$ for $i=1,2$;

3. The sensitivity of the production function to $a_{2}$ and the complementarity among actions is not affected by input quality, i.e. $\frac{\partial^{3} f}{\partial a_{2}^{2} \partial s}=0$ and $\frac{\partial^{3} f}{\partial a_{1} \partial a_{2} \partial s}=0$;

4. The sensitivity of the production function to $a_{1}$ and $a_{2}$ and the complementarity among effort types is not affected by the incentive scheme parameter $\alpha$, i.e. $\frac{\partial^{3} f}{\partial a_{i}^{2} \partial \alpha}=0$ for $i=1,2$ and $\frac{\partial^{3} f}{\partial a_{1} \partial a_{2} \partial \alpha}=0$.

The first condition ensures that marginal returns to each effort are decreasing. The second conditions implies that direct effects are more important than indirect effects when exogenous parameters change. The third condition mandates that both the sensitivity of the production function to the amount of effort spent on collecting eggs and the degree of complementarity among effort types do not change with input quality. Yet, notice that no assumption is made regarding the degree of complementarity between the two effort types. Finally, the fourth 
condition ensures that the concavity of the production function with respect to both worker efforts and the degree of complementarity among them among them are not affected by the parameter defining the composite performance measure on the contract.

From the previous first order conditions, taking derivatives respect to $\alpha$ we get

$$
\begin{gathered}
\frac{\partial^{2} f}{\partial a_{1 i}^{2}} \frac{\partial a_{1 i}}{\partial \alpha}+\frac{\partial^{2} f}{\partial a_{1 i} \partial a_{2 i}} \frac{\partial a_{2 i}}{\partial \alpha}=\frac{1-\theta_{i}}{\alpha^{2}} \\
\frac{\partial^{2} f}{\partial a_{1 i} \partial a_{2 i}} \frac{\partial a_{1 i}}{\partial \alpha}+\frac{\partial^{2} f}{\partial a_{2 i}^{2}} \frac{\partial a_{2 i}}{\partial \alpha}=-\frac{\theta_{i}}{\alpha^{2}}
\end{gathered}
$$

Clearing $\partial a_{2 i} / \partial \alpha$ from the second equation above and replacing it in the first one we get

$$
\Gamma \frac{\partial a_{1 i}}{\partial \alpha}=\frac{\theta_{i}}{\alpha^{2}} f_{a_{1 i} a_{2 i}}+\frac{1-\theta_{i}}{\alpha^{2}} f_{a_{2 i}}^{\prime \prime}
$$

where $\Gamma=\left[\frac{\partial^{2} f}{\partial a_{1 i}^{2}} \frac{\partial^{2} f}{\partial a_{2 i}^{2}}-\left(\frac{\partial^{2} f}{\partial a_{1 i} \partial a_{2 i}}\right)^{2}\right]>0$ as given by conditions 1 and 2 above, $f_{a_{1 i} a_{2 i}}=$ $\frac{\partial^{2} f}{\partial a_{1 i} \partial a_{2 i}}$ and $f_{a_{2 i}}^{\prime \prime}=\frac{\partial^{2} f}{\partial a_{2 i}^{2}}<0$. It follows that

(i) If $f_{a_{1 i} a_{2 i}}=0$, there is no relationship among effort types, $a_{1 i}$ is determined only by the first equation in A.8, and we are back to the model outlined in Section 2;

(ii) If $f_{a_{1 i} a_{2 i}}<0$, workers efforts are substitutes in production, the right hand side of equation A.9 is negative, and $\partial a_{1 i} / \partial \alpha<0$;

(iii) If $f_{a_{1 i} a_{2 i}}>0$, workers efforts are complements in production, then $\partial a_{1 i} / \partial \alpha<0$ iff $0<\theta_{i}<\frac{-f_{a_{2 i}}^{\prime \prime}}{f_{a_{1 i} a_{2 i}-f_{a_{2 i}}^{\prime \prime}}}<1$.

Taking the derivative of equation A.9 with respect to $s$ and considering condition 3 above we get:

$$
\frac{\partial^{3} f}{\partial a_{1 i}^{2} \partial s} f_{a_{2 i}}^{\prime \prime} \frac{\partial a_{1 i}}{\partial \alpha}+\Gamma \frac{\partial^{2} a_{1 i}}{\partial \alpha \partial s}=0
$$

From which we can obtain the same predictions we have in Section 2 as given by

(iv) If $\partial^{3} f / \partial a_{1 i}^{2} \partial s>0$, then $\partial^{2} a_{1 i} / \partial \alpha \partial s<0$;

(v) or, if $\partial^{3} f / \partial a_{1 i}^{2} \partial s<0$, then $\partial^{2} a_{1 i} / \partial \alpha \partial s>0$. 
We can follow the same procedure to get the comparative statistics with respect to $\theta_{i}$. Starting again from the first order conditions and taking derivatives we get:

$$
\begin{gathered}
\frac{\partial^{2} f}{\partial a_{1 i}^{2}} \frac{\partial a_{1 i}}{\partial \theta_{i}}+\frac{\partial^{2} f}{\partial a_{1 i} \partial a_{2 i}} \frac{\partial a_{2 i}}{\partial \theta_{i}}=\frac{1}{\alpha} \\
\frac{\partial^{2} f}{\partial a_{1 i} \partial a_{2 i}} \frac{\partial a_{1 i}}{\partial \theta_{i}}+\frac{\partial^{2} f}{\partial a_{2 i}^{2}} \frac{\partial a_{2 i}}{\partial \theta_{i}}=\frac{1}{\alpha}
\end{gathered}
$$

Clearing $\partial a_{2 i} / \partial \theta_{i}$ from equation $\mathrm{A} .12$ and replacing it in $\mathrm{A} .11$ we get

$$
\Gamma \frac{\partial a_{1 i}}{\partial \theta_{i}}=\frac{1}{\alpha}\left(f_{a_{2 i}}^{\prime \prime}-f_{a_{1 i} a_{2 i}}\right)
$$

Conditions 1 and 2 imply that $\partial a_{1 i} / \partial \theta_{i}<0$ for any value of $f_{a_{1 i} a_{2 i}}$. Taking derivatives of the previous equation respect to $\alpha$ together with given condition 4 above we obtain

$$
\Gamma \frac{\partial^{2} a_{1 i}}{\partial \alpha \partial \theta_{i}}=-\frac{\left(f_{a_{2 i}}^{\prime \prime}-f_{a_{1 i} a_{2 i}}\right)}{\alpha^{2}}
$$

From which it follows $\partial^{2} a_{1 i} / \partial \alpha \partial \theta_{i}>0$.

An example of a production function that satisfies all the conditions we have included in this section and is applicable to our setting is $y_{i}=\frac{1}{s_{i}}\left(a_{1 i}-a_{1 i}^{2}\right)+\left(a_{2 i}-a_{2 i}^{2}\right)+a_{2 i}\left(a_{1 i}+s_{i}\right)+\varepsilon_{i}$ where $0 \leq s \leq 1$ measures input quality, and $\varepsilon_{i}$ is an idiosyncratic shock.

Participation Starting from the expression of the worker's certainty equivalent, we can take its derivative with respect to $\alpha$ and get

$$
\frac{\partial \hat{u}}{\partial \alpha}=y_{i}-a_{i}+\alpha \frac{\partial y_{i}}{\partial \alpha}+\left(1-\alpha-\theta_{i}\right) \frac{\partial a_{1 i}}{\partial \alpha}-\theta_{i} \frac{a_{2 i}}{\partial \alpha}-\eta \alpha \sigma^{2}
$$

Since $\frac{\partial y_{i}}{\partial \alpha}=\frac{\partial f\left(s_{i}, a_{1 i}, a_{2 i}\right)}{\partial a_{1 i}} \frac{\partial a_{1 i}}{\partial \alpha}+\frac{\partial f\left(s_{i}, a_{1 i}, a_{2 i}\right)}{\partial a_{2 i}} \frac{\partial a_{2 i}}{\partial \alpha}$ and the worker chooses the optimal effort levels, we can replace the first order condition in equation A.16 and obtain 


$$
\frac{\partial \hat{u}}{\partial \alpha}=y_{i}-a_{1 i}^{*}-\eta \alpha \sigma^{2}
$$

Taking the derivative with respect to $\theta_{i}$, and given $\frac{\partial y_{i}}{\partial \theta_{i}}=\frac{\partial f\left(s_{i}, a_{1 i}\right)}{\partial a_{1 i}} \frac{\partial a_{1 i}}{\partial \theta_{i}}+\frac{\partial f\left(s_{i}, a_{2 i}\right)}{\partial a_{2 i}} \frac{\partial a_{2 i}}{\partial \theta_{i}}$, we can replace again the first order condition to get

$$
\frac{\partial^{2} \hat{u}}{\partial \alpha \partial \theta_{i}}=-\frac{1-\theta_{i}}{\alpha} \frac{\partial a_{1 i}}{\partial \theta_{i}}+\frac{\theta_{i}}{\alpha} \frac{\partial a_{2 i}}{\partial \theta_{i}}
$$

where $\frac{\partial a_{1 i}}{\partial \theta_{i}}<0$ and following the same procedure as in step 2, we can show that $\frac{\partial a_{2 i}}{\partial \theta_{i}}<0$. Then, $\partial^{2} \hat{u} / \partial \alpha \partial \theta_{i}>0$ if $\left(\partial a_{1 i} / \partial \theta_{i}\right) /\left(\partial a_{1 i} / \partial \theta_{i}+\partial a_{2 i} / \partial \theta_{i}\right)>\theta_{i}$. An increase in $\alpha$ increases expected utility on the job relatively more for workers with higher marginal cost $\theta_{i}$.

Finally, utility on the job also depends on the assigned input quality. It is possible to show that if $\partial^{3} f\left(s_{i}, a_{1 i}, a_{2 i}\right) / \partial a_{1 i}^{2} s_{i} \geq 0$ then $\partial^{2} a_{1 i} / \partial \theta_{i} \partial s_{i} \leq 0$ but $\partial^{2} a_{i} / \partial \theta_{i} \partial s_{i}$ could be positive or negative. Then, we get:

(vi) If $\partial^{2} a_{2 i} / \partial \theta_{i} \partial s_{i} \geq 0$ then $\partial^{3} \hat{u} / \partial \alpha \partial \theta_{i} \partial s_{i} \geq 0$

(vii) If $\partial^{2} a_{2 i} / \partial \theta_{i} \partial s_{i} \leq 0$ and $\left(\partial a_{1 i} / \partial \theta_{i} \partial s\right) /\left(\partial a_{1 i} / \partial \theta_{i} \partial s+\partial a_{2 i} / \partial \theta_{i} \partial s\right)>\theta_{i}$, then $\partial^{3} \hat{u} / \partial \alpha \partial \theta_{i} \partial s_{i} \geq$ 0.

Using the same production function suggested before we obtain that $\frac{\partial a_{1 i}}{\partial \theta_{i}}=-\frac{2 s}{\alpha(1-s)}<0$ and $\frac{\partial a_{2 i}}{\partial \theta_{i}}=-\frac{(1+s)}{\alpha(1-s)}<0$, which implies that $\frac{\partial^{2} \hat{u}}{\partial \alpha \partial \theta_{i}}>0$ if $\theta_{i}<\frac{2}{3+(1 / s)}$. Moreover, $\frac{\partial a_{1 i}}{\partial \theta_{i} \partial \alpha}=\frac{\partial a_{2 i}}{\partial \theta_{i} \partial \alpha}=$ $-2 / \alpha(1-s)^{2}<0$, which implies that $\frac{\partial^{3} \hat{u}}{\partial \alpha \partial \theta_{i} \partial s_{i}} \geq 0$ if $\theta_{i}<1 / 2$.

\section{A.4 Threshold for Incentive Pay}

This section shows theoretically that the presence of a threshold for piece rate pay does not confound our interpretation of empirical results.

In the presence of a threshold for piece rate pay, equation 4 of Section 2 still defines the optimal level of effort for those workers who achieve the threshold in expectations. For all other workers, exerting effort does not bring any benefit. They will therefore exert a minimum level 
of effort $\bar{a}<a_{i}^{*}$. Let $\tilde{a}_{i}$ be the level of effort such that worker $i$ reaches the threshold in expectations. The worker will exert effort $\bar{a}$ if $a_{i}^{*} \leq \tilde{a}_{i}$, and $a_{i}^{*}$ otherwise.

In our application, the concavity of output with respect to effort is lower when input quality increases, meaning $\partial^{3} f\left(s_{i}, a_{i}\right) / \partial a_{i}^{2} s_{i}>0$. In Section 5 , we test accordingly whether an increase in $\alpha$ decreases effort relatively more for workers handling inputs of higher quality. The presence of a threshold for incentive pay can potentially confound the interpretation of results if $\partial \tilde{a}_{i} / \partial \alpha>0$ and $\partial^{2} \tilde{a}_{i} / \partial \alpha \partial s_{i}>0$. Under these conditions, an increase in $\alpha$ induces more workers to exert the minimum effort level $\bar{a}$, and relatively more so when input quality is higher.

To explore this possibility, we derive an explicit solution for $a_{i}^{*}$ by incorporating the condition $\partial^{3} f\left(s_{i}, a_{i}\right) / \partial a_{i}^{2} s_{i}>0$ parsimoniously in a production function of the form

$$
y_{i}=\frac{1}{s_{i}}\left(a_{i}-a_{i}^{2}\right)+\varepsilon_{i}
$$

Solving for $a_{i}$ in the first order condition of the worker's maximization problem in equation 4 of Section 2 yields

$$
a_{i}^{*}=\frac{1}{2}-\frac{s_{i}}{2}\left(1-\frac{1-\theta_{i}}{\alpha}\right)
$$

Notice that under the assumption that $1>\theta_{i} \geq 1-\alpha$ we have $a_{i}^{*}<1 / 2$. Let the threshold for piece rate pay be equal to $r$. The level of effort $\tilde{a}_{i}$ such that the worker reaches the threshold in expectations is given by the solution to

$$
\frac{\alpha}{s_{i}}\left(a_{i}-a_{i}^{2}\right)+(1-\alpha) a_{i}=r
$$

It can be shown that $\partial \tilde{a}_{i} / \partial \alpha<0$, and $\partial^{2} \tilde{a}_{i} / \partial \alpha \partial s_{i}<0$. This means that, as $\alpha$ increases, less workers will exert the minimum effort level $\bar{a}$, and even less so when input quality is higher. The presence of a threshold for piece rate pay would therefore work against us in finding evidence that is consistent with our model predictions. 


\section{Récents cahiers de recherche du CIREQ Recent CIREQ Working Papers}

La liste complète des cahiers de recherche du CIREQ est disponible à l'adresse suivante: http://www.cireqmontreal.com/cahiers-de-recherche .

The complete list of CIREQ's working papers is available at the following address : http://www.cireqmontreal.com/cahiers-de-recherche.

24-2018 Horan, S., "Threshold Luce Rules", novembre 2018, 35 pages

25-2018 Beauchêne, D., J. Li, M. Li, "Ambiguous Persuasion", octobre 2018, 74 pages

26-2018 Horan, S., "Random Consideration and Choice : A Case Study of "Default" Options", novembre 2018, 27 pages

27-2018 Marcoux, M., "Sharp Test for Equilibrium Uniqueness in Discrete Games with a Flexible Information Structure", décembre 2018, 38 pages

01-2019 Marcoux, M., "Games with Unobservable Heterogeneity and Multiple Equilibria : An Application to Mobile Telecommunications", février 2019, 45 pages

02-2019 Mueller, H. et C. Rauh, "The Hard Problem of Prediction for Conflict", avril 2019, 46 pages

03-2019 Galindo da Fonseca et J.A., P. Pannella, "The Housing Boom and Selection into Entrepreneurship", mai 2019, 30 pages

04-2019 Galindo da Fonseca, J.A., "Unemployment, Entrepreneurship and Firm Outcomes", mai 2019, 96 pages

05-2019 Galindo da Fonseca, J.A. et C. Berubé, "Spouses and Entrepreneurship", mai 2019, 45 pages

06-2019 Galindo da Fonseca, J.A. et I. Snoddy, "Entrepreneurship, Outside Options and Constrained Efficiency", mai 2019, 22 pages

07-2019 Benchekroun, H., A.R. Chaudhuri, D. Tanseem, "On the Impact of Trade in a Common Property Renewable Resource Oligopoly", mai 2019, 28 pages

08-2019 Duffy, J., J.H. Jiang, H. Xie, "Experimental Asset Markets with an Indefinite Horizon", juillet 2019, 58 pages

09-2019 Rauh, C., "Measuring Uncertainty at the Regional Level Using Newspaper Text", août 2019, 28 pages

10-2019 Aguirregabiria, V., M. Marcoux, "Imposing Equilibrium Restrictions in the Estimation of Dynamic Discrete Games", septembre 2019, 45 pages

11-2019 Pelli, M., J. Tschopp, N. Bezmaternykh, K.M. Eklou, "In the Eye of the Storm : Firms and Capital Destruction in India", octobre 2019, 43 pages

12-2019 Amodio, F., G. Chiovelli, S. Hohmann, "The Employment Effects of Ethnic Politics", décembre 2019, 65 pages 